Article

\title{
The Use of Stereoscopic Satellite Images to Map Rills and Ephemeral Gullies
}

\author{
Federica Fiorucci *, Francesca Ardizzone, Mauro Rossi and Dino Torri \\ CNR IRPI, via Madonna Alta 126, 06128 Perugia, Italy; \\ E-Mails: francesca.ardizzone@irpi.cnr.it (F.A.); mauro.rossi@irpi.cnr.it (M.R.); \\ dibiti2001@gmail.com (D.T.)
}

* Author to whom correspondence should be addressed; E-Mail: federica.fiorucci@irpi.cnr.it.

Academic Editors: Richard Gloaguen, Magaly Koch and Prasad S. Thenkabail

Received: 11 February 2015 / Accepted: 15 October 2015 / Published: 27 October 2015

\begin{abstract}
Accurate mapping and measurement of erosion channels is necessary to accurately estimate the impact of channeled erosion in an area. Field surveys can provide optimal quantitative results, but they are only applicable to small areas. Recently, photogrammetric techniques have been applied to small format aerial photographs that were taken by UAVs. Few studies have applied photogrammetry for mapping and measuring single permanent gullies using very high resolution stereoscopic satellite images. We explore the use of such images to map rills and ephemeral gullies and to measure the length, width and depth of individual erosion channels to estimate the eroded volumes. The proposed methodology was applied to the Collazzone area of Central Italy. All of the channel characteristics were determined using GeoEye- $1^{\circledR}$ panchromatic stereoscopic satellite images of the $48-\mathrm{km}^{2}$ study area and a 3D floating cursor. We identified, mapped, and measured the lengths of 555 channel segments. The top width and depth could be measured in only a subset of the channel segments (the SMC subset). The SMC data were used to determine the coefficients of the power law relationship between the rill/gully volume and length $\left(V=a L^{b}\right)$ and the uncertainties due to the channel depth measurements and the cross-sectional shape. The field data of the rill and gully volumes were within the estimated uncertainty. We defined a decision rule to distinguish rills from gullies on the basis of the segment length and applied the corresponding power law relationship that was derived from the SMC subset to estimate the eroded volume of the entire dataset. The erosion values that were calculated at different scales $\left(0.680 \mathrm{Mg} \cdot \mathrm{ha}^{-1}\right.$ at the catchment scale, $28.4 \mathrm{Mg} \cdot \mathrm{ha}^{-1}$ on the parcels affected by erosion) are consistent with values found in the literature. Our results indicate that erosion
\end{abstract}


at the catchment scale can be considered moderate, whereas the erosion at the field scale exceeds the tolerance limit, which is consistent with data that have been summarized and/or discussed by several authors.

Keywords: linear erosion; floating cursor; VHR satellite images; rill-gully threshold; soil denudation; Central Italy

\section{Introduction}

During intense rainfall events, soil erosion often excavates two types of channels: rills and ephemeral gullies. Rills are usually small, with typical widths of approximately $10-20 \mathrm{~cm}$ and depths of $10-15 \mathrm{~cm}$. Ephemeral gullies are larger channels that are approximately 50-100 cm wide and 40-100 cm deep. Rills and ephemeral gullies are typical erosion products that are associated with cropland and are obliterated by normal tillage practices as well as by land levelling when the excavated channels become too large. Permanent gullies are characterized by larger channels that can be as much as $500 \mathrm{~m}$ wide and up to $300 \mathrm{~m}$ deep. Detailed discussions on the definition of and the differences between rills and gullies can be found in Poesen et al. [1] and Torri and Borselli [2].

The importance of rills and ephemeral gullies is not limited to erosion but is also related to sediment and water connectivity in the landscape. Rills and ephemeral gullies increase the connectivity of the slope to the base slope and to the drainage network, which affects the chances of local floods and contributes to damage to infrastructure and private property $[3,4]$. For these reasons, assessing their presence and monitoring their changes may contribute to a better understanding of floods and post-disaster management. Hence, increasing the number of techniques for detecting and evaluating rill and ephemeral gully erosion is beneficial to disaster management and prevention. Because permanent gullies are permanent features of the landscape, they will not be discussed in this paper, and the term gully will refer only to ephemeral gullies.

The mapping of rills and ephemeral gullies and the measuring of soil loss when rills and ephemeral gullies are generated or further excavated are not simple procedures. Ephemeral gullies are usually eradicated soon after the triggering rainfall [5] and can even go undetected when gauges in the instrumented basin become clogged by excessive sediment [6]. As a result, most intense events are measured based on the dimensions of rills and gullies that are carved into the slopes [7]. Collecting data on rill and ephemeral gully erosion is made even more complex by the temporary nature of the phenomenon, which is easily removed by tillage equipment or bulldozers or masked by the growth of vegetation, making prompt and fast mapping surveys of rills and gullies extremely important [5]. Different techniques have been used to compile rill and gully maps. Traditionally, reconnaissance field surveys [8-12] or interpretations of topographic maps and aerial photographs have been used to obtain information on the number, density, size, type and location of head basins [8,13]. Over the last 20 years, various remote sensing data and techniques have been used for rill and gully detection and mapping, including stereoscopic aerial photographs that were taken shortly after an event, sets of multi-temporal aerial photographs [14-16] and the visual or digital analysis of high-resolution DEMs that were obtained 
from kite, airborne Lidar sensors and Unmanned Aerial Vehicles (UAVs) [17-20] or from terrestrial photographs [21-23].

Examples of rill and gully erosion measurements with photogrammetric techniques abound in the literature. Nachtergaele and Poesen [5] assessed the use of stereoscopic aerial photographs to determine the erosion rates of ephemeral gullies in Belgium. The authors suggested a correction factor that correlates the measured length on aerial photographs to the actual length of the channels. Watson and Evans [24] compared the measurements of eroded volumes from a field survey with the estimated volumes that were obtained through perspective photographs for an area in northeastern Scotland. Despite the limitations, these techniques offer a quick and easy method to estimate soil loss in areas that are dominated by channeled erosion processes. Keech [25] used multi-temporal stereoscopic aerial photographs at a scale of 1:25,000 that were taken in 1946, 1956, 1968, 1971, 1976, and 1984 to map gullies in the Mhondoro Communal Area of Zimbabwe. The depth of the gullies and eroded volumes were estimated using photo-analytical plotters.

Satellite images can be used to map erosion features. In addition to filters and classification techniques [26-28], low- and medium-resolution images were used in the past to map large- and medium-sized gullies $[29,30]$ or to estimate the total area that is affected by gully erosion.

Over the past decade, the technological development of satellite sensors, the availability of images with ever higher spatial resolution and the improvement of digital visualization and analysis techniques have encouraged investigators to utilize satellite images to detect and map slope processes. Previously, automatic and semiautomatic techniques were used to map channeled erosion features. Bouaziz et al. [31] used a pixel-based maximum likelihood classification, whereas Vrieling et al. [32] used MODIS and Aster NDVI to evaluate erosion risk. New high-resolution satellite images and improved digital imaging technology also open up new possibilities for object-based image analysis [33] in the mapping of rills and gullies. Shrutri et al. [34] developed a knowledge-based generic method for gully assessment by coupling object oriented analysis and spatially dynamic erosion modeling in the sub-humid to semi-arid region of Sehoul, Morocco.

An inexpensive and rapid method for mapping permanent gullies based on the exploitation of very high-resolution (VHR) satellite images (GeoEye- $1^{\circledR}$ and Cnes SPOT ${ }^{\circledR}$ images) that are accessed via Google Earth ${ }^{\circledR}$ has been tested in Ethiopia [35,36]. The availability of VHR satellite stereoscopic images (Cartosat-1, 2.5 m resolution) has recently been used as an alternative to stereoscopic aerial photographs to quantify the erosion of permanent gullies in northern Australia [37].

In the abovementioned studies, the gullies that were examined using satellite images were permanent medium- to large-size features of the landscape. Ephemeral gullies and rills were ignored because of both their small dimensions and low permanence in the landscape. Most research focused on mapping erosion features using monoscopic satellite images rather than measuring the morphological characteristics (i.e., width, depth, length) of erosion channels. Of the previous studies, only Sattar et al. [37] used $2.5 \mathrm{~m}$ stereoscopic satellite images to measure the depth of large permanent gully channels.

In this work, we present the results of an experiment that tests the efficiency of using digital stereoscopic satellite images to rapidly quantify ephemeral gully erosion over a large area. The main objectives of this paper are to (1) evaluate the capability of mapping and measuring ephemeral gullies and rills using stereoscopic satellite images and (2) assess the reliability and associated error of satellite-based rill and gully measurements to estimate eroded volumes over large areas. 


\section{Study Area}

The study area is located in Umbria, Central Italy (Figure 1A,B), at the coordinates $42^{\circ} 49^{\prime} \mathrm{N}$ and $12^{\circ} 27^{\prime} \mathrm{E}$, and covers an area of approximately $48 \mathrm{~km}^{2}$, with an elevation that ranges from $146 \mathrm{~m}$ to $634 \mathrm{~m}$. The area is characterized by outcrops of sedimentary rocks (Figure 2A), including (i) alluvial deposits (5\%), chiefly along the main valley bottoms; (ii) Plio-Pleistocene continental deposits (52\%), sand (10\%) and clay (2\%); (iii) Pleistocene travertine deposits (6\%); (iv) Miocene layered sandstone and marl (12\%); and (v) Lias to Oligocene thinly layered limestone (13\%) [38-41].

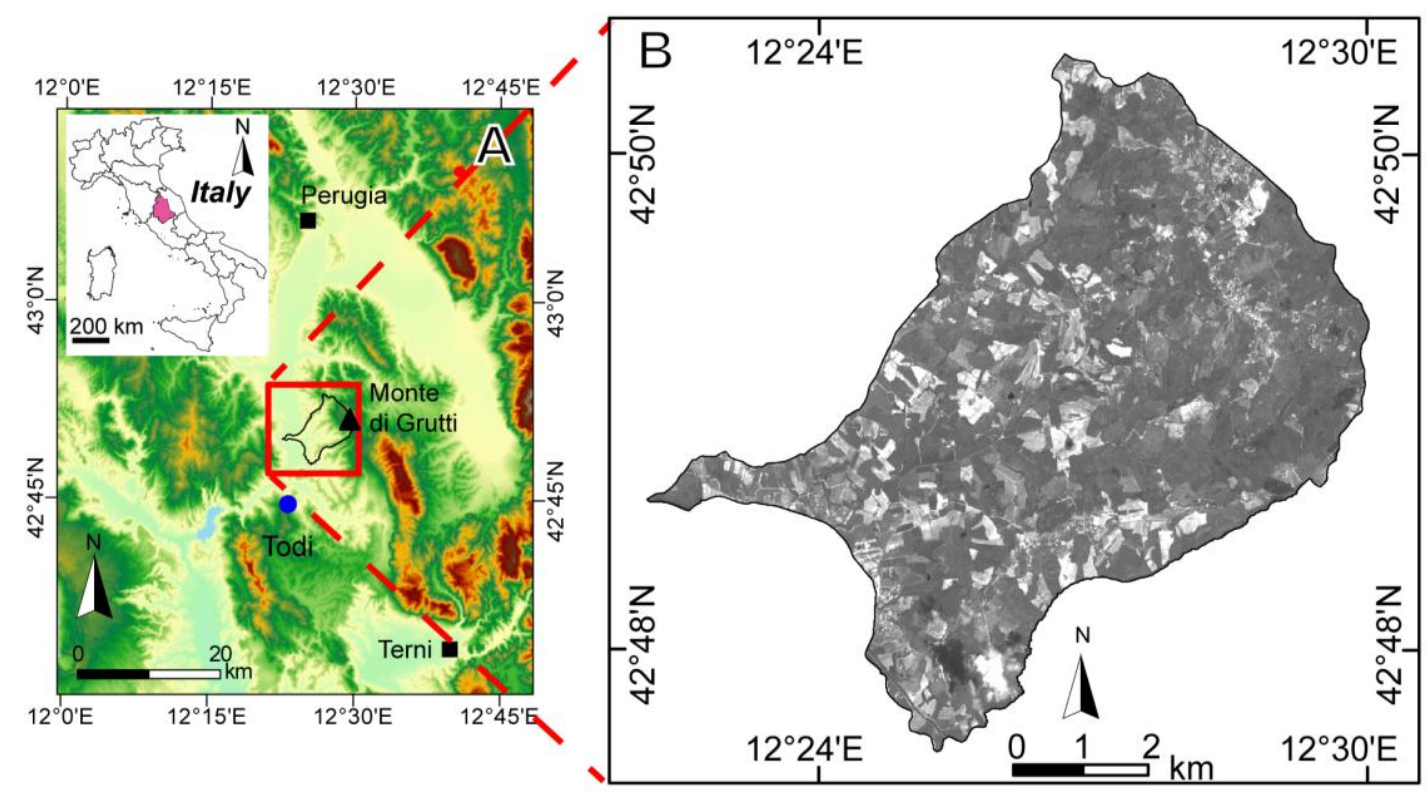

Figure 1. Location map. (A) The Umbria Region is in pink (inset), and the shaded relief map shows the location of the study area (DEM 20 meter resolution obtained from interpolation of counter lines). The blue dot represents the Todi rain gauge. (B) GeoEye- ${ }^{\circledR}$ image taken on 27 May 2010.

The climate of the study area is Mediterranean, with most of the precipitation falling between October and December. The historical rainfall time series (1951-2013) for the Todi rain gauge $\left(42^{\circ} 46^{\prime} 36^{\prime \prime} \mathrm{N}\right.$ and $12^{\circ} 24^{\prime} 18^{\prime \prime} \mathrm{E}$; elevation: $283 \mathrm{~m}$ asl), (Figure 1A) indicates that the average annual rainfall is $841.1 \mathrm{~mm}$ and that the maximum and minimum average monthly precipitation levels occur in November (116 mm) and July $(38 \mathrm{~mm})$, respectively. The maximum observed monthly rainfall was $456 \mathrm{~mm}$, recorded in October, and the maximum rainfall amount in $24 \mathrm{~h}$ was $124 \mathrm{~mm}$, recorded in September.

The soil moisture regime in the study area is a typical xeric moisture regime of areas with cold and damp winters and dry summers. The soil texture is medium-fine, and the soil thickness ranges from $0.25 \mathrm{~m}$ to $1.5 \mathrm{~m}$. Five profiles are available in the study area, and these profiles exhibit a well-developed A horizon (45-50 cm) with deterioration due to ploughing and a B horizon up to $90 \mathrm{~cm}$ deep (Soil map of the Regione Umbria, 1:250,000 (http://www.agricoltura.regione.umbria.it)).

The land cover (Figure 2B) is characterized by croplands $(60.22 \%)$, forests $(23.08 \%)$, urban areas $(8.99 \%)$, pastures $(6.03 \%)$, vineyards and orchards $(1.46 \%)$ and water $(0.23 \%)$. Farming in the area favors the development of slope failures (landslides, channeled and sheet erosion). The slope dynamics are characterized by landslides, mainly soil slides and earth flows $[42,43]$, which are triggered by 
prolonged rainfall and rapid snow melting [44]. No studies have focused on gully erosion, despite the fact that ephemeral gullies in croplands are a common feature in this area.

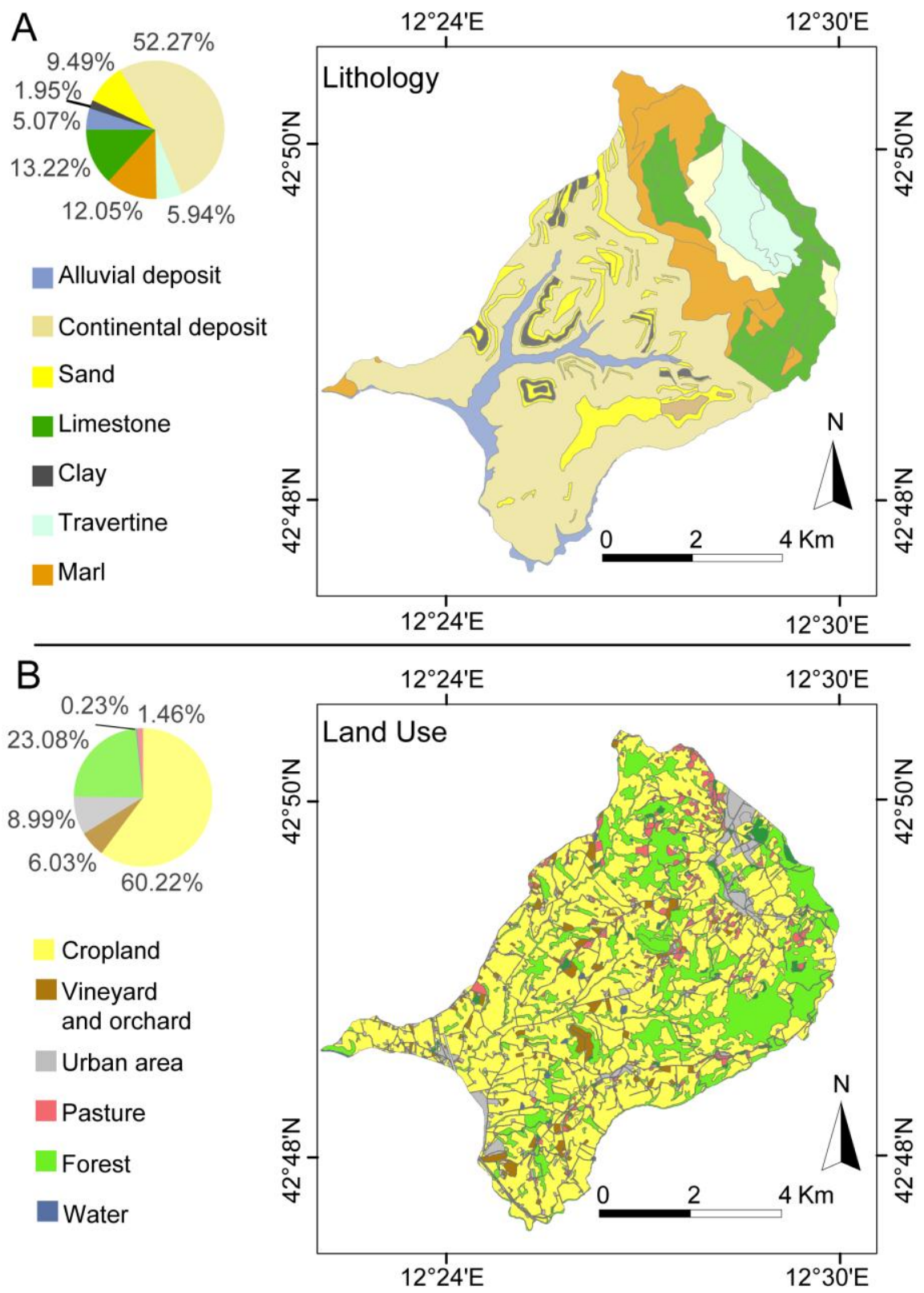

Figure 2. (A) Simplified lithological map and pie chart for the study area, modified after Servizio Geologico d'Italia [39]. The figures represent the percentages of the lithologies that are present in the study area. (B) Land use map and pie chart for the study area. The figures represent the percentages of the soil use in the study area.

\section{Materials}

Two pairs of stereoscopic panchromatic satellite images are available for the test area: one taken by the WorldView- ${ }^{\circledR}$ satellite on 8 March 2010 and the other from the GeoEye- $1^{\circledR}$ satellite on 27 May 2010 (Table 1). The GeoEye- $1{ }^{\circledR}$ and WorldView- $1{ }^{\circledR}$ images are in the panchromatic band with a $0.5 \times 0.5 \mathrm{~m}$ ground sample distance. All the images feature Rational Polynomial Coefficients (RPCs), which indicate the image's position relative to the ground. 
Table 1 Characteristics of the stereoscopic satellite images that were acquired by the GeoEye- $1^{\circledR}$ and WorldView- $1{ }^{\circledR}$ satellites.

\begin{tabular}{ccccc}
\hline & Date & Overlap (\%) & Azimuth Angle $\left(^{\circ}\right)$ & Elevation Angle $\left(^{\circ}\right.$ ) \\
\hline WorldView- $1^{\circledR}$ & 8 March 2010 & 70 & 77.30 & 57.90 \\
${\text { WorldView- } 1^{\circledR}}^{\circledR}$ & 8 March 2010 & 70 & 141.1 & 52.70 \\
GeoEye-1 ${ }^{\circledR}$ & 27 May 2010 & 95 & 8.41 & 72.26 \\
GeoEye-1 $^{\circledR}$ & 27 May 2010 & 95 & 199.51 & 71.99 \\
\hline
\end{tabular}

The ERDAS IMAGINE and Leica Photogrammetry Suite (LPS) software were used to prepare the oriented stereo-pair. The WorldView- ${ }^{\circledR}$ stereo-pair was oriented using the model sensor for the internal orientation and the RPC files for the external orientation. The stereo-pair GeoEye- ${ }^{\circledR}$ was oriented using the sensor model and the associated RPC. The oriented model was improved in accuracy by adding 26 ground control points (GCPs). The estimated error of the oriented model given by the root mean square error (RMSE) is 0.11 pixels. In detail, the GCPs' RMSEs are as follows: $\mathrm{X}$ is $1.75 \mathrm{~m}, \mathrm{Y}$ is $0.99 \mathrm{~m}$, and $\mathrm{Z}$ is $2.01 \mathrm{~m}$. Files of this block type are compatible with the Stereo Analyst ArcGIS ${ }^{\circledR}$ extension.

\section{Methods}

\subsection{Rainfall Data and Event Reconstruction}

To investigate the triggering of rills and gullies, we analyzed the rainfall that was recorded by the Todi rain gauge station (Figure 1). Two periods were analyzed: (i) one preceding the date of the images acquisition (27 May 2004), and (ii) one preceding the date of the field survey activities (30 April 2013). This is needed to understand whether the rainfall events in the two periods are similar.

Because abundant rills and gullies are visible in the 27 May 2004, GeoEye- $1{ }^{\circledR}$ stereo image but not in the 8 March 2004, WordView- $1{ }^{\circledR}$ stereo image, we assume that they developed between 8 March and 27 May.

An analysis of the 30-min cumulative rainfall data series allowed us to identify multiple rainfall events within the selected time period. This analysis was performed using the automated classification procedure for rainfall events that was proposed by Rossi et al. [45-47], which classifies a rainfall event as a period of consecutive hours with a cumulative rainfall of more than $1 \mathrm{~mm}$. The total cumulative rainfall (C), the duration (D) and the average intensity (I) were calculated for each event in the selected period.

\subsection{Use of Planar's SD StereoMirror ${ }^{T M}$ Technology}

A 3D view of the GeoEye- $1{ }^{\circledR}$ pan-sharpened images was generated in the Stereo Analyst module [48], and the Planar StereoMirror ${ }^{\mathrm{TM}}$ [49] technology was used to visualise the 3D view.

Planar's SD StereoMirror ${ }^{\mathrm{TM}}$ technology works with two active matrix liquid crystal display (AMLCD) monitors that are oriented at a $110^{\circ}$ angular distance. A passive beam splitter mirror bisects the angle between the two monitors. One side of the glass mirror has a reflective coating, and the other side has an anti-reflective coating, thereby allowing the user to see the two stereo-images of the monitors at the same time [50]. When stereo-pair images from the two monitors are viewed through crossed polarizing glasses, the user only sees the left-eye image with one eyepiece and the right-eye image with the other eyepiece due to different polarization angles (Figure 3). The result is a single, fused 
stereoscopic image. The Stereo Analyst extension works with a floating cursor; in this case, the cursor resides on the topographic surface and is used to draw vector features. A 3D floating cursor consists of an independent cursor that is displayed on the left image and an independent cursor that is displayed on the right image of the stereo-pair. When images are not viewed in stereo, the 3D floating cursor appears to be two separate cursors that may or may not rest on the same feature. However, when viewed in stereo, the two cursors fuse to create the perception of a 3D floating cursor. In this type of workstation, the scroll wheel moves up or down to either increase or decrease the elevation $(Z)$ of the 3D floating cursor. With this digitizing device, the technician has full control over the 3D floating cursor and can position it accurately and reliably within the stereo-pair. Every time the 3D floating cursor is adjusted, new 3D coordinates ( $\mathrm{E}$ and $\mathrm{N}$ coordinates and elevation) are computed using the sensor model information that is associated with each oriented image in the pair. Importantly, an elevation model is not required to collect reliable 3D GIS data when oriented images are used. However, the manual adjustment of the position of the $3 \mathrm{D}$ floating cursor requires the continuous attention of the operator.
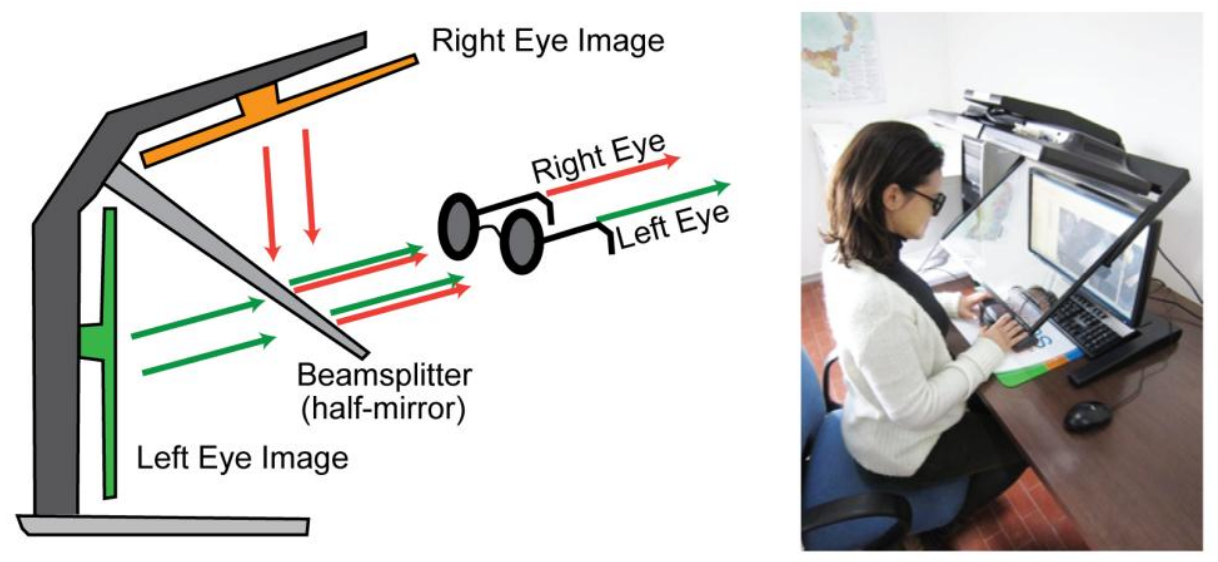

Figure 3. Schematic of the StereoMirror ${ }^{\mathrm{TM}}$ technology (http://www.planar.com/media/ 211327/mn-planar-sd2220w.pdf).

Using the 3D floating cursor it is possible to measure relative heights of objects from the difference of elevation. Stereoscopic satellite images provide low-accuracy estimates of the absolute elevation (z) (1-2 m) but high-precision measurements of the relative heights of objects [51].

\subsection{Mapping and Measuring Rills and Gullies on Satellite Stereo Images}

Rills and gullies can be recognized in stereoscopic panchromatic satellite images through the heuristic interpretation of photographic characteristics, such as shape, color (grey shade), tone and texture. In particular, linear erosion features, such as rills and gullies, are characterized by long, narrow shapes and light tones. The light tones that highlight recently eroded channels are caused by increased reflectance, which results from several differences between the channel surface and the inter-channel degraded seed-bed surface (e.g., surface roughness, organic matter content, soil moisture, and vegetation cover).

The visibility of the ephemeral gullies and rills within the images depends on morphometric factors, such as the width of the channel, the illumination conditions and the characteristics of the image (contrast and resolution). The contrast is the most important characteristic for image interpretation; features can 
only be distinguished if they have noticeably different levels of brightness. The advantage of using satellite images (and digital images in general) is the ability to dynamically vary the contrast (Figure 4).
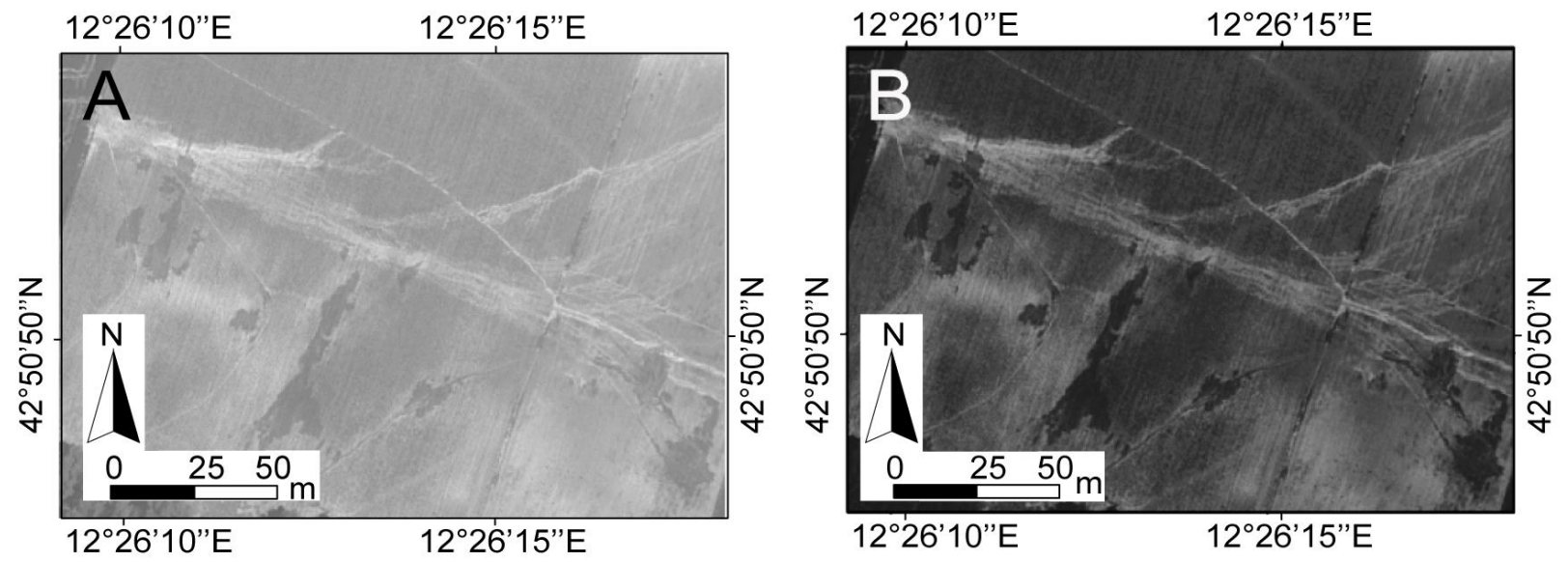

Figure 4. (A) Example of a ploughed field on an unstretched image and (B) on the enhanced image that was obtained by stretching the histogram values of the scene.

All of the visible channels were mapped and edited in a 3D GIS environment through the photointerpretation of stereoscopic satellite images. The central lines of the channels were digitized in the flow direction. Each channel segment is delimited by two consecutive nodes, where a node is either an intersection point between channels or a channel head/end (Figure 5A). The length of every channel segment was obtained as an attribute of the GIS database. The top widths and depths of the channels could be measured only in a subset of the channels (SMC) that was chosen based on their visibility on the images. The bottom widths of the channels could not be measured without ambiguity.

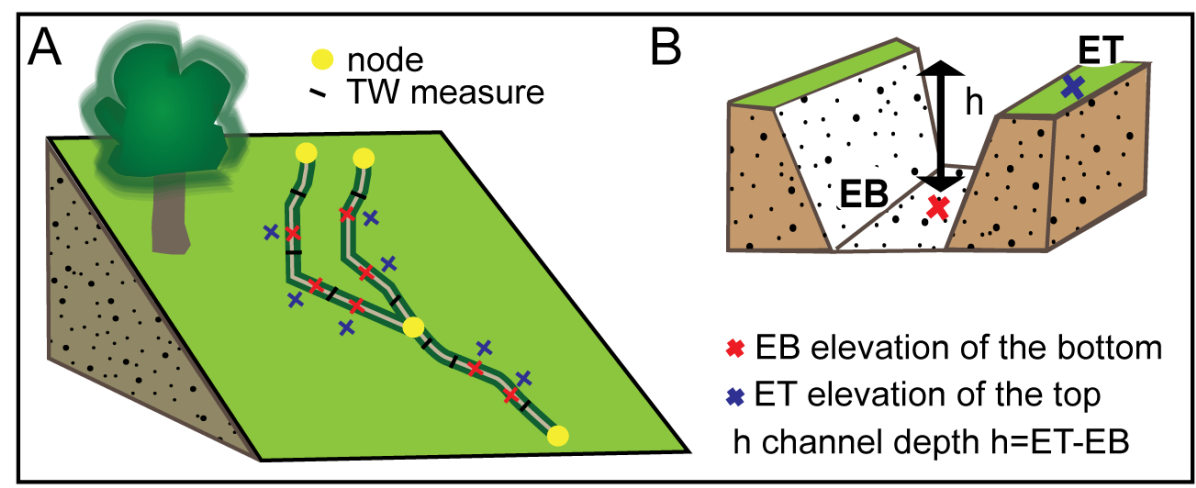

Figure 5. (A) Sketch of the channel mapping on satellite images. The yellow dots represent the nodes. Each channel is delimited by two consecutive nodes. (B) Sketch of the channel depth measurements. The crosses represent the positions of the floating cursor.

All of the attributes of the SMC channel segments were measured using the 3D floating cursor [50] directly on the stereo-pair in a 3D environment. For each segment, we measured a series of top widths $(T W)$ and depths $(h)$. The top width of the channel was measured as the length of the segment that is transverse (orthogonal) to the channel and could be identified from the differences in the shades of grey 
inside and outside the channel. The channel depth is the difference between the elevations of the side (top) of the channel segment and the channel bottom (Figure 5B).

\subsubsection{Rill and Gully Volume Estimation from Satellite Measurements}

The volume of each of the SMC channel segments was calculated. From the series of $T W$ and $h$ values that were measured along the channel segment, we calculated the average values of $\overline{T W}$ and $\bar{h}$. Hence, each channel segment was characterized by its length $(L), \overline{T W}$ and $\bar{h}$. We assumed a trapezoidal cross-sectional shape of the channel with a bottom width $B W$ that is estimated to be a fraction of $\overline{T W}$. This proportion was estimated based on the average $B W / T W$ ratio that was measured in the field (Section 5.3).

The CS of each channel segment was then estimated using the following equation:

$$
\mathrm{CS}=\left[\frac{(1+k) \times \overline{T W}}{2}\right] \times \bar{h}
$$

where $k=B W / T W$, to obtain the volume,

$$
\mathrm{V}=\mathrm{CS} \times \mathrm{L}
$$

\subsection{Rill and Gully Field Measurements}

In the spring of 2013, a field survey was conducted in the study area to measure the characteristics of the rill and gully channels and to calculate their volumes. The gullies and rills were measured using the procedure that was described in Casalí et al. [10] for the "detailed measurement of section characteristic lengths with a tape." The sections were chosen and measured every meter or every five meters along the channel depending on the channel length (Figure 6A). In each section, the depth of the channel was measured with a variable pitch according to the width of the channel (from $5 \mathrm{~cm}$ to $50 \mathrm{~cm}$ for wider channels) (Figure 6B). The sections were then drawn in a CAD system to automatically calculate the area of each channel's cross section (CS). Finally, the volume of each channel segment $\left(\mathrm{V}_{c}\right)$ was calculated using the equation

$$
\mathrm{V}_{\mathrm{c}}=\sum\left(\frac{\mathrm{CS}_{\mathrm{i}}+\mathrm{CS}_{\mathrm{i}+1}}{2}\right) \times \mathrm{L}_{\mathrm{i}}
$$

where $\mathrm{C} S_{i}$ is the area of a section, $\mathrm{C} S_{i+1}$ is the area of the next section, and $l_{i}$ is the length of the channel between $\mathrm{C} S_{i}$ and $\mathrm{C} S_{i+1}$ (Figure 6C).

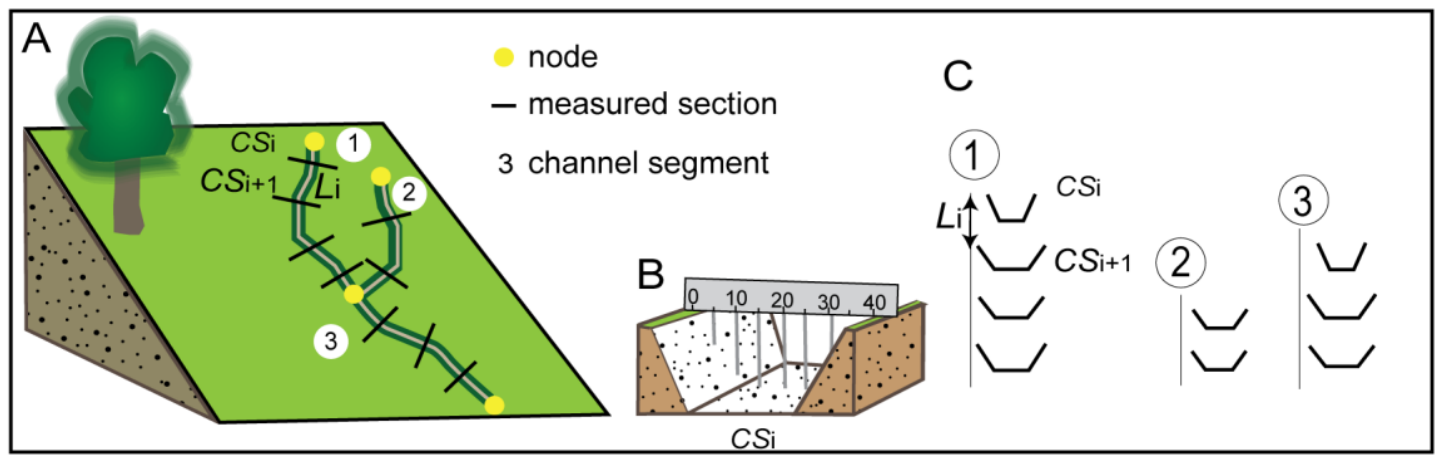

Figure 6. Sketch of the field mapping procedure. (A) Measurement points in the field. (B) Cross section measurements. (C) Measurements of the channel volumes. 


\subsection{Channel Classification}

We adopted the cross section dimension threshold $[52,53]$ as the criterion to distinguish between the two erosion phenomena (rills and ephemeral gullies), which states that the limit between rills and gully is a cross-sectional area of $0.0929 \mathrm{~m}^{2}$ (1 square foot). This criterion was applicable to the field dataset and to the SMC subset.

\subsection{Uncertainty of the Measurements}

\subsubsection{Accuracy of Satellite Height Measurements}

We selected specific locations in the field as reference points (hereafter denoted as the height measurement survey) to assess the accuracy (i.e., the errors) of the height measurements that were derived from the satellite images using the floating cursor (see Section 4.2). The survey was conducted in October 2010 when we measured the heights of 24 stable objects (e.g., pavement, walls, and buildings) because they are constant over time, unlike the rills and gully channels. The field measurements were compared with the heights of the corresponding objects that were calculated from the satellite images (Section 5.4.1).

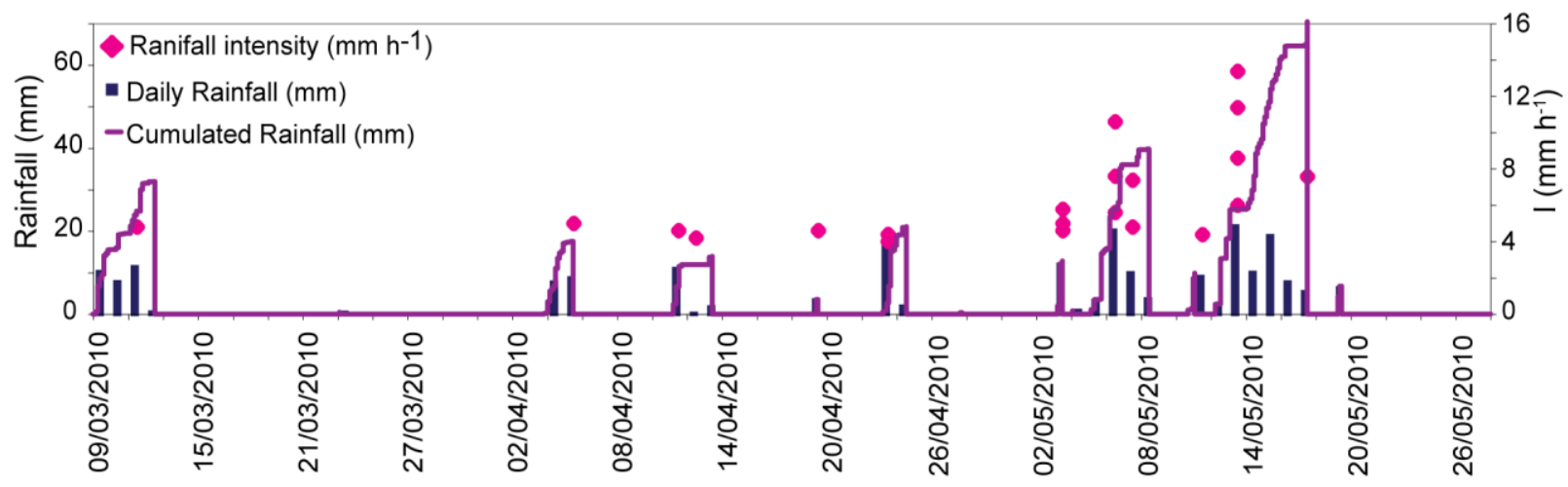

Figure 7. The pink dots represent the rainfall intensity in $\mathrm{mm} \cdot \mathrm{h}^{-1}$, the blue bars indicate the daily rainfall, and the violet line represents the cumulative rainfall. Only events that exceed $4 \mathrm{~mm} \cdot \mathrm{h}^{-1}$ are shown.

\subsubsection{Volume-Length Relationship from Satellite Data and Associated Uncertainty}

Several authors [54-58] have proposed that the length, $L$, of a gully or rill channel can serve as an estimator of the eroded volume according to the following power law equation:

$$
V=a L^{b}
$$

where $a$ is a coefficient and $b$ is a power law exponent. In a bi-logarithmic diagram, the power law equation is linear, with $b$ controlling the angular coefficient and expressing the rate of variation of $V$ depending on $L$, and $a$ is the scale factor.

During the analysis of the SMC subset that were measured from the satellite images, we first calculated the best-fitting values of $a$ and $b$ in the $V-L$ relationship and then estimated the uncertainty that was associated with the fit using a bootstrap procedure $[59,60]$ and by considering the error that was 
associated with the satellite depth measurements (see Section 4.6.1). The analysis was performed using $\mathrm{R}$, a free software environment for statistical computing and graphics [61].

The best-fitting procedure for the calculation of the power law parameters was performed using a classical least-squares approach.

We executed the following steps to estimate the uncertainty that was associated with the fit:

I. The uncertainty that was associated with the channel depth satellite measurements (Section 5.4.1) was modelled by assuming a normal distribution for the residuals in the linear regression model.

II. We used the Kolmogorov-Smirnov test (KS) and the quantile-quantile (QQ) plot of the modelled and measured errors to determine whether the normal distribution was appropriate for modeling the uncertainty that was associated with the channel depth satellite measurements.

III. The normal distribution was used to generate $n$ synthetic series of channel heights that were associated with each channel segment. Then, knowing the width and the length of the channel segments that were measured from the satellite stereo-images, we derived a synthetic series of channel volumes.

IV. The $n$ synthetic series of channel volumes that were associated with the satellite channel length measurements were fitted using a least-squares approach to estimate the $n$ power law parameters ( $a$ and $b$ ).

V. The 35 th and the 65 th percentile values of the $n$ power law parameters ( $a$ and $b$ ) were assumed to be representative of the uncertainty that was associated with the satellite $V-L$ relationship estimates.

The procedure was applied to the rills and gullies separately, considering $n=10,000$ synthetic series to evaluate the V-L relationship parameters and the associated uncertainty.

\subsection{3. $T W / B W$ Ratio and Associated Uncertainty.}

It is only possible to measure the $T W$ dimension on the satellite images. The cross sections are evaluated based on an average value of the ratio $B W / T W$, which is calculated on the rills and gullies that were surveyed in the field; this process introduces a simplification and is a source of error. To assess its importance, we can assume that the shape of the cross section is approximated by different geometrical shapes. The $C S$ formula can be varied continuously to change the section shape from rectangular to triangular through all possible trapezoids. $C S$ can be calculated as follows:

$$
\mathrm{CS}=\left[\frac{(1+k) \times T W}{2}\right] \times h
$$

where $\mathrm{k}=B W / T W$.

This is a general form that results in a rectangle when $B W / T W=1$ and a triangle when $B W / T W=0$. Thus, we calculated the effect of changing the value of the ratio from 0 to 1 on the calculated volume (Section 5.4.2). 


\subsection{Eroded Volumes and Denudation}

The V-L power law relationships that were obtained from the analysis of the SMC segments were used to estimate the eroded volumes for all 555 channels that were mapped on the satellite images. For the 500 channels for which the widths, depths and associated cross sections were not measured, we could not define whether the channels were rills or gullies and thus could not choose which equation to use. An alternative solution consists of evaluating the volumes for the extreme cases in which the channels were all rills or all gullies. The two components of the total soil erosion (rill and gully) can be added to obtain the total erosion if the weights are known. Because we want to evaluate the erosion, the weighing factor should be the channel volume. Unfortunately, we cannot estimate the ratio (component volume)/(total volume) from the SMC or field survey data because in both cases, the rill and gully samples are not representative of the population; the selection was aimed at determining the volume/length relationship. Because the segment length is the only parameter that is available for all of the segments, we must define a criterion that is based on the segment length to be applicable to the entire satellite dataset. Hence, we propose a mixed approach that is based on segment length: we use the rill volume equation if the segment is shorter than the minimum gully length and the gully volume equation if it is longer the maximum rill length. If the segment is between minimum gully length and maximum rill length, we arbitrarily use the average of the rill and gully volumes.

In both extreme cases (all rills and all gullies), we used the $V$ - $L$ power law relationships that were derived using the 35 th, 50th and 65th percentile values of the $a$ and $b$ parameters to simulate the total eroded volumes and their uncertainties. The values that correspond to the mixed approach were calculated only for the 50th percentiles. We estimated the erosion based on an approximate density $(\gamma)$ of the eroded material of $\gamma=1.6 \mathrm{Mg} \cdot \mathrm{m}^{-3}$ [62].

\section{Results}

\subsection{Rainfall Events}

The total recorded rainfall from 8 March to 27 May 2010, was $217 \mathrm{~mm}$. Intense rainfall events occurred between 3 May and 8 May with $32 \mathrm{~mm}$ of cumulative rainfall in $138 \mathrm{~h}$ and between 11 May and 17 May with $66 \mathrm{~mm}$ of cumulative rainfall in $160 \mathrm{~h}$ (violet line in Figure 7). During the 3-8 May event, the most intense rainfall was recorded on 6 May and amounted to $20 \mathrm{~mm}$ (blue bars in Figure 7), which corresponds to an intensity of $10 \mathrm{~mm} \cdot \mathrm{h}^{-1}$ (pink dots in Figure 7). During the 11-17 May event, the most intense rainfall was recorded on 13 May and totaled $21 \mathrm{~mm}$, whit an intensity of $14 \mathrm{~mm} \cdot \mathrm{h}^{-1}$ (pink dots in Figure 7).

The rainfall conditions during the period that preceded the field survey (1 January to 30 April 2013) were analyzed (Figure 8). The total recorded rainfall in this period was $338 \mathrm{~mm}$. The most intense rainfall events occurred on 12 March, with $45 \mathrm{~mm}$ of rainfall in 24 hours (blue bars in Figure 8), whit an intensity of $14 \mathrm{~mm} \cdot \mathrm{h}^{-1}$. Another intense event was recorded on 28 April with a maximum intensity of $12 \mathrm{~mm}^{-1}$. 


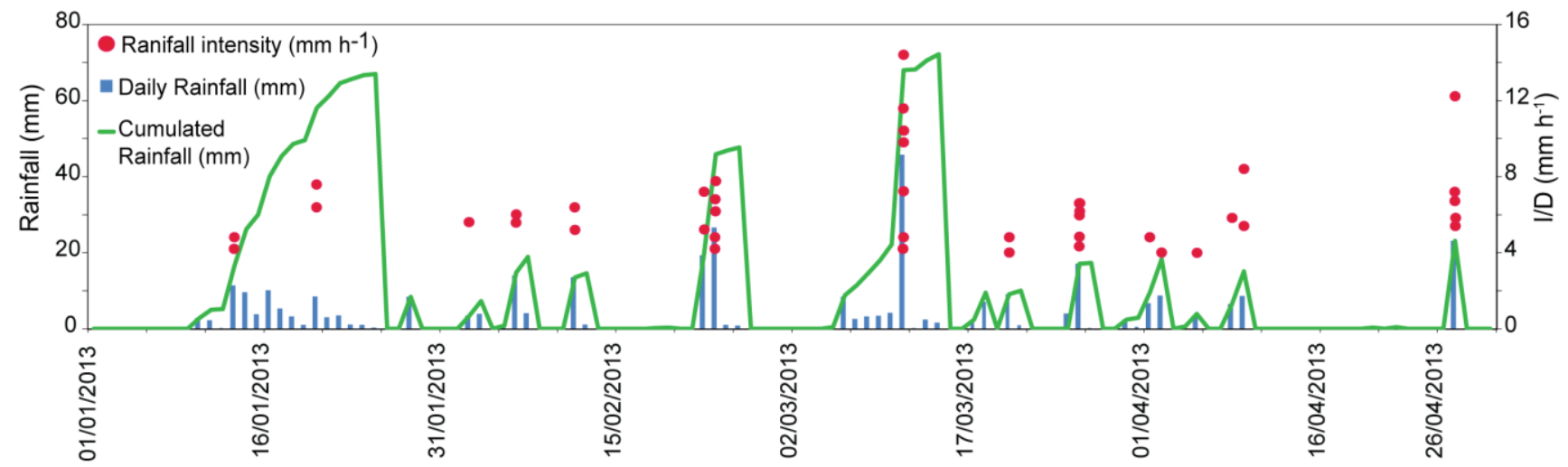

Figure 8. Rainfall measurements from the Todi rain gauge from 1 January to 30 April 2013. The purple dots represent the rainfall intensity in $\mathrm{mm} \cdot \mathrm{h}^{-1}$, the blue bars represent the daily rainfall, and the green line represents the cumulative rainfall. Only events that exceed $4 \mathrm{~mm} \cdot \mathrm{h}^{-1}$ are shown.

\subsection{Mapping and Measuring Rills and Ephemeral Gullies on Satellite Images}

We mapped 555 channels using the method that was described in Section 4.3. The erosion channels were distributed over 19 cropland under seed-bed conditions (Figures 9 and 10).

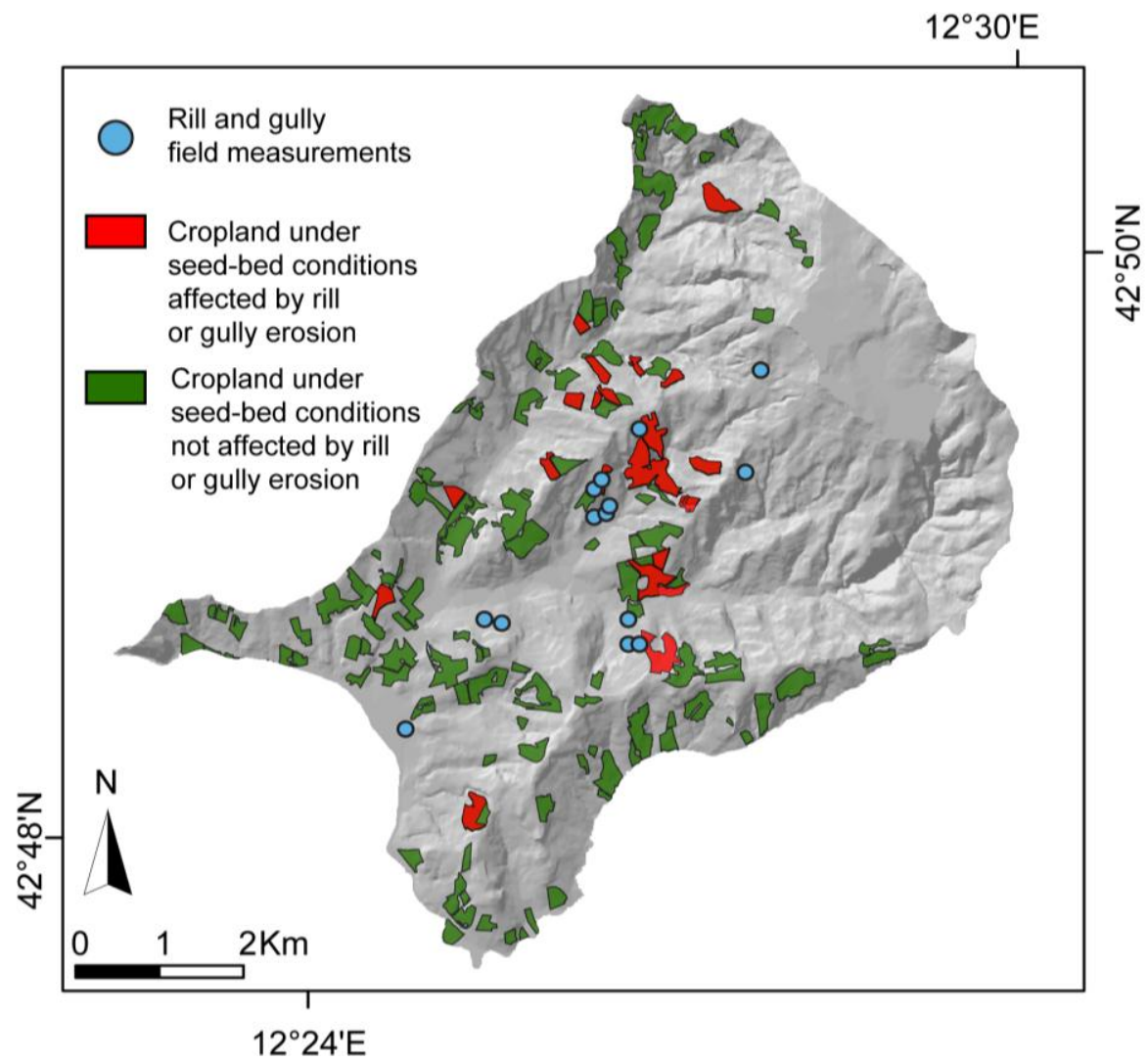

Figure 9. Map that shows the locations of the field measurements of the rills and gullies (blue dots), the cropland under seed-bed conditions that were affected by channeled erosion (red polygons), and the cropland under seed-bed conditions not affected by rill and gully erosion (green polygons). 

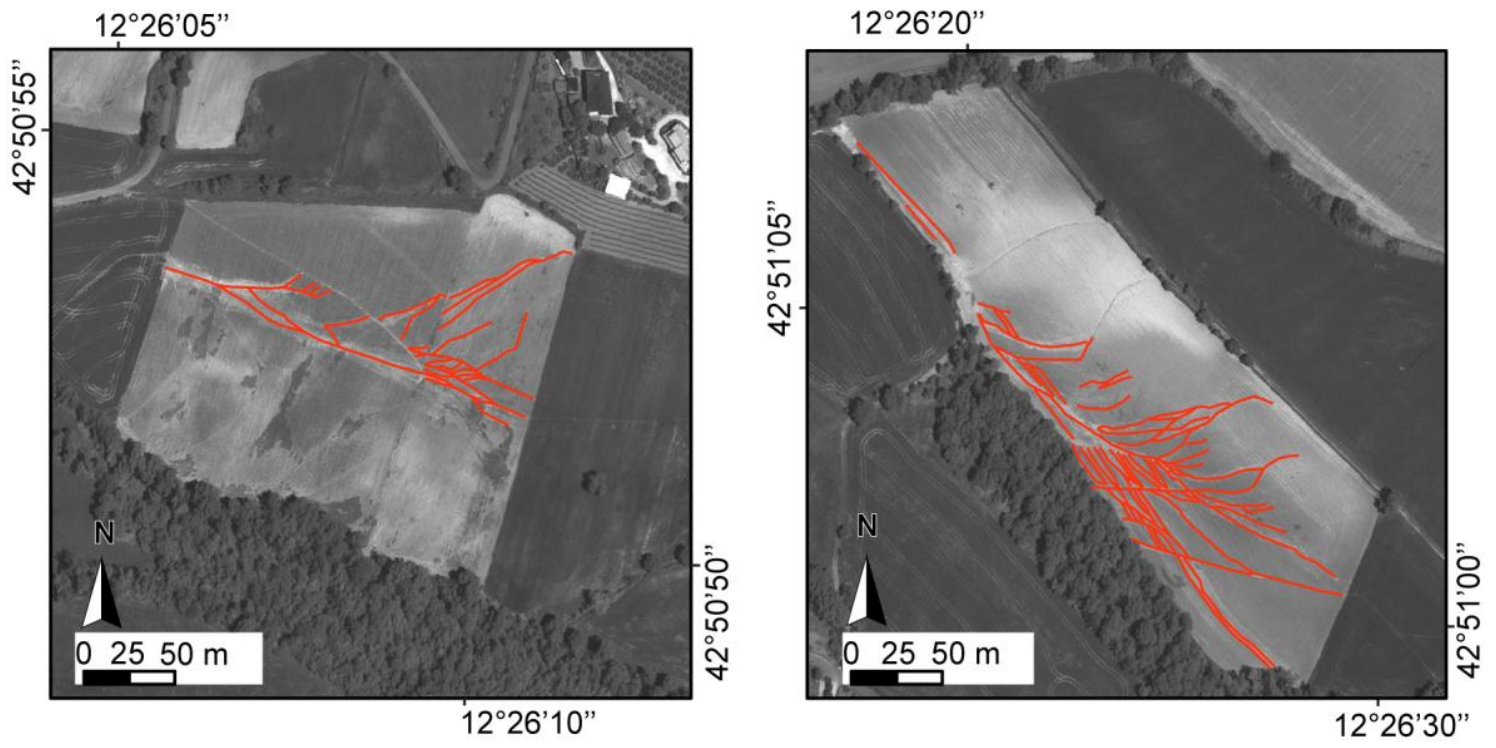

Figure 10. Examples of rills and ephemeral gullies that were mapped on the satellite images.

The average channel length is $26.5 \mathrm{~m}(\sigma=26.2 \mathrm{~m})$, and the total length of the channels is $1.4 \times 10^{4} \mathrm{~m}$. We measured the top widths and depths of a subset of 55 channels segments (see Table 2) of the SMC subset (14 rills and 41 gullies). Rills and gullies are classified based on the cross-sectional dimensions [53]. The rill lengths range from 7.33 to $43.4 \mathrm{~m}$, the depths range from 0.08 to $0.23 \mathrm{~m}$, top widths range from 0.50 to $1.3 \mathrm{~m}$, and the cross-sectional areas range from 0.052 to $0.092 \mathrm{~m}^{2}$. The gully lengths vary between 10.61 and $113.44 \mathrm{~m}$, the depths range between 0.08 and $0.33 \mathrm{~m}$, top widths range from 0.52 to $2.6 \mathrm{~m}$, and the cross-sectional areas range from 0.11 to $0.36 \mathrm{~m}^{2}$.

For each of the 55 channels, the volume was calculated as described in Section 4.3.1. The volumes of the rills range between $0.39 \mathrm{~m}^{3}$ and $3.61 \mathrm{~m}^{3}$, and the volumes of the gullies range between $1.84 \mathrm{~m}^{3}$ and $32.80 \mathrm{~m}^{3}$.

Table 2. Measurements of the 55 channels that were obtained from the stereo satellite images.

$L$ : channel segment length; $C S$ : cross-sectional area; $\overline{T W}$ : major base (top width); $\bar{h}$ channel depth, $B W$ : minor base (bottom width; equal to $0.6 \mathrm{TW}$ ); $R$ : rill; $E G$ : ephemeral gully.

\begin{tabular}{cccccccc}
\hline $\begin{array}{c}\text { Channel } \\
\#\end{array}$ & $\begin{array}{c}\boldsymbol{L} \\
\mathbf{m}\end{array}$ & $\begin{array}{c}\overline{\boldsymbol{T}} \boldsymbol{\mathbf { m }} \\
\mathbf{m}\end{array}$ & $\begin{array}{c}\mathbf{B W} \\
\mathbf{m}\end{array}$ & $\begin{array}{c}\overline{\boldsymbol{h}} \\
\mathbf{m}\end{array}$ & $\begin{array}{c}\mathbf{C S} \\
\mathbf{m}^{\mathbf{2}}\end{array}$ & $\begin{array}{c}\text { Volume } \\
\mathbf{m}^{\mathbf{3}}\end{array}$ & Type \\
\hline 1 & 7.34 & 0.82 & 0.49 & 0.08 & 0.05 & 0.39 & $\mathrm{R}$ \\
2 & 9.40 & 0.82 & 0.49 & 0.08 & 0.05 & 0.49 & $\mathrm{R}$ \\
3 & 15.56 & 0.8 & 0.48 & 0.10 & 0.06 & 1.00 & $\mathrm{R}$ \\
4 & 28.03 & 0.5 & 0.30 & 0.16 & 0.06 & 1.79 & $\mathrm{R}$ \\
5 & 9.70 & 1.05 & 0.63 & 0.08 & 0.07 & 0.65 & $\mathrm{R}$ \\
6 & 14.17 & 1.05 & 0.63 & 0.08 & 0.07 & 0.95 & $\mathrm{R}$ \\
7 & 18.57 & 1.05 & 0.63 & 0.08 & 0.07 & 1.25 & $\mathrm{R}$ \\
8 & 25.17 & 0.5 & 0.30 & 0.17 & 0.07 & 1.71 & $\mathrm{R}$ \\
9 & 29.18 & 0.5 & 0.30 & 0.17 & 0.07 & 1.98 & $\mathrm{R}$ \\
10 & 13.76 & 1.05 & 0.63 & 0.09 & 0.08 & 1.04 & $\mathrm{R}$ \\
11 & 11.23 & 1.20 & 0.72 & 0.08 & 0.08 & 0.86 & $\mathrm{R}$ \\
12 & 11.79 & 1.30 & 0.78 & 0.08 & 0.08 & 0.98 & $\mathrm{R}$ \\
\hline
\end{tabular}


Table 2. Cont.

\begin{tabular}{|c|c|c|c|c|c|c|c|}
\hline $\begin{array}{c}\text { Channel } \\
\#\end{array}$ & $\begin{array}{l}L \\
\mathbf{m}\end{array}$ & $\begin{array}{c}\overline{T W} \\
\mathbf{m}\end{array}$ & $\begin{array}{c}\mathbf{B W} \\
\mathbf{m}\end{array}$ & $\begin{array}{l}\bar{h} \\
\mathbf{m}\end{array}$ & $\begin{array}{l}\mathbf{C S} \\
\mathbf{m}^{2}\end{array}$ & $\begin{array}{c}\text { Volume } \\
\mathbf{m}^{3}\end{array}$ & Type \\
\hline 13 & 43.43 & 1.30 & 0.78 & 0.08 & 0.08 & 3.61 & $\mathrm{R}$ \\
\hline 14 & 32.15 & 0.50 & 0.30 & 0.23 & 0.09 & 2.96 & $\mathrm{R}$ \\
\hline 15 & 36.42 & 1.46 & 0.87 & 0.08 & 0.09 & 3.40 & EG \\
\hline 16 & 22.63 & 1.20 & 0.72 & 0.1 & 0.10 & 2.17 & EG \\
\hline 17 & 38.02 & 1.50 & 0.90 & 0.08 & 0.10 & 3.65 & EG \\
\hline 18 & 39.12 & 1.50 & 0.90 & 0.08 & 0.10 & 3.76 & EG \\
\hline 19 & 20.81 & 0.64 & 0.38 & 0.19 & 0.10 & 2.02 & EG \\
\hline 20 & 27.16 & 1.50 & 0.90 & 0.09 & 0.11 & 2.93 & EG \\
\hline 21 & 29.70 & 1.73 & 1.04 & 0.08 & 0.11 & 3.29 & EG \\
\hline 22 & 55.96 & 0.93 & 0.56 & 0.16 & 0.12 & 6.66 & EG \\
\hline 23 & 44.99 & 0.52 & 0.31 & 0.3 & 0.12 & 5.61 & EG \\
\hline 24 & 17.86 & 2.00 & 1.20 & 0.08 & 0.13 & 2.29 & EG \\
\hline 25 & 16.05 & 0.8 & 0.48 & 0.22 & 0.14 & 2.26 & EG \\
\hline 26 & 26.48 & 0.9 & 0.54 & 0.2 & 0.14 & 3.81 & EG \\
\hline 27 & 12.18 & 1.05 & 0.63 & 0.18 & 0.15 & 1.84 & EG \\
\hline 28 & 12.98 & 0.87 & 0.522 & 0.22 & 0.15 & 1.99 & EG \\
\hline 29 & 37.00 & 1.2 & 0.72 & 0.16 & 0.15 & 5.68 & EG \\
\hline 30 & 34.85 & 1.00 & 0.60 & 0.2 & 0.16 & 5.58 & EG \\
\hline 31 & 18.34 & 2.6 & 1.56 & 0.08 & 0.17 & 3.05 & EG \\
\hline 32 & 30.96 & 0.88 & 0.52 & 0.25 & 0.18 & 5.45 & EG \\
\hline 33 & 11.00 & 0.90 & 0.54 & 0.25 & 0.18 & 1.98 & EG \\
\hline 34 & 44.81 & 1.35 & 0.81 & 0.17 & 0.18 & 8.23 & EG \\
\hline 35 & 49.58 & 0.80 & 0.48 & 0.29 & 0.19 & 9.20 & EG \\
\hline 36 & 25.93 & 0.90 & 0.54 & 0.26 & 0.19 & 4.85 & EG \\
\hline 37 & 31.34 & 1.24 & 0.74 & 0.2 & 0.20 & 6.22 & EG \\
\hline 38 & 40.70 & 1.10 & 0.66 & 0.23 & 0.20 & 8.24 & EG \\
\hline 39 & 28.35 & 1.50 & 0.90 & 0.17 & 0.20 & 5.78 & EG \\
\hline 40 & 20.92 & 1.20 & 0.72 & 0.23 & 0.22 & 4.62 & EG \\
\hline 41 & 62.63 & 1.40 & 0.84 & 0.2 & 0.22 & 14.03 & EG \\
\hline 42 & 70.42 & 1.80 & 1.08 & 0.16 & 0.23 & 16.23 & EG \\
\hline 43 & 10.61 & 1.00 & 0.6 & 0.29 & 0.23 & 2.46 & EG \\
\hline 44 & 113.43 & 1.58 & 0.94 & 0.2 & 0.25 & 28.67 & EG \\
\hline 45 & 80.74 & 1.54 & 0.92 & 0.21 & 0.26 & 20.89 & EG \\
\hline 46 & 20.87 & 0.98 & 0.58 & 0.33 & 0.26 & 5.40 & EG \\
\hline 47 & 16.90 & 1.7 & 1.02 & 0.2 & 0.27 & 4.60 & EG \\
\hline 48 & 26.02 & 1.8 & 1.08 & 0.19 & 0.27 & 7.12 & EG \\
\hline 49 & 18.25 & 1.56 & 0.93 & 0.22 & 0.27 & 5.01 & EG \\
\hline 50 & 25.01 & 1.46 & 0.87 & 0.26 & 0.30 & 7.60 & EG \\
\hline 51 & 105.80 & 1.25 & 0.75 & 0.31 & 0.31 & 32.80 & EG \\
\hline 52 & 43.60 & 1.48 & 0.88 & 0.27 & 0.32 & 13.94 & EG \\
\hline 53 & 54.77 & 1.50 & 0.90 & 0.27 & 0.32 & 17.74 & EG \\
\hline 54 & 57.06 & 2.15 & 1.29 & 0.2 & 0.34 & 19.63 & EG \\
\hline 55 & 53.16 & 1.56 & 0.93 & 0.29 & 0.36 & 19.24 & EG \\
\hline
\end{tabular}




\subsection{Rill and Gully Field Measurements}

The field measurements and relative volume estimates of the rills and gullies are reported in Table 3 .

Table 3. Measurements of the rills and ephemeral gullies that were surveyed in the field. $L$ : channel segment length; $C S$ : cross-sectional area; $B W$ : minor base (bottom width); $T W$ : major base (top width); EG: gully; R: rill.

\begin{tabular}{|c|c|c|c|c|c|c|c|c|c|c|}
\hline Id & Type & $\begin{array}{l}L \\
\mathbf{m}\end{array}$ & $\# C S$ & $\begin{array}{c}C S \\
\text { Average } \\
\mathbf{m}^{\mathbf{2}} \\
\end{array}$ & $\begin{array}{c}C S \\
\text { Max } \\
\mathbf{m}^{2} \\
\end{array}$ & $\begin{array}{c}C S \\
\text { Min } \\
\mathbf{m}^{2} \\
\end{array}$ & $\begin{array}{c}T W \\
\text { Max } \\
\mathbf{m} \\
\end{array}$ & $\begin{array}{c}T W \\
\text { Min } \\
\mathbf{m} \\
\end{array}$ & $\begin{array}{c}\text { Volume } \\
\mathbf{m}^{3}\end{array}$ & $\begin{array}{c}\text { Average } \\
\text { BW/TW } \\
\text { ratio } \\
\end{array}$ \\
\hline 1 & $\mathrm{R}$ & 47 & 20 & 0.069 & 0.11 & 0.02 & 0.90 & 0.34 & 3.32 & 0.7 \\
\hline 2 & $\mathrm{R}$ & 8.8 & 7 & 0.050 & 0.08 & 0.03 & 1.20 & 0.40 & 0.55 & 0.7 \\
\hline 3 & $\mathrm{R}$ & 19 & 7 & 0.069 & 0.04 & 0.01 & 0.50 & 0.34 & 0.44 & 0.5 \\
\hline 4 & $\mathrm{R}$ & 30 & 8 & 0.061 & 0.10 & 0.03 & 1.00 & 0.40 & 1.50 & 0.7 \\
\hline 5 & $\mathrm{R}$ & 3.2 & 2 & 0.085 & 0.09 & 0.08 & 0.50 & 0.50 & 0.30 & 0.5 \\
\hline 6 & $\mathrm{R}$ & 32.5 & 7 & 0.062 & 0.14 & 0.08 & 1.30 & 0.51 & 1.88 & 0.7 \\
\hline 7 & EG & 34 & 7 & 0.103 & 0.25 & 0.07 & 1.70 & 1.00 & 4.14 & 0.6 \\
\hline 8 & $\mathrm{R}$ & 30 & 7 & 0.082 & 0.10 & 0.04 & 1.20 & 0.60 & 2.13 & 0.6 \\
\hline 9 & EG & 22.4 & 7 & 0.144 & 0.20 & 0.09 & 1.20 & 0.48 & 2.68 & 0.7 \\
\hline 10 & EG & 13 & 4 & 0.205 & 0.27 & 0.12 & 1.08 & 0.50 & 2.23 & 0.5 \\
\hline 11 & $\mathrm{R}$ & 22.5 & 8 & 0.091 & 0.11 & 0.20 & 1.17 & 0.30 & 1.15 & 0.5 \\
\hline 12 & EG & 18.8 & 6 & 0.250 & 0.36 & 0.16 & 1.19 & 0.77 & 3.80 & 0.3 \\
\hline 13 & EG & 10 & 5 & 0.198 & 0.24 & 0.14 & 1.00 & 0.70 & 1.85 & 0.3 \\
\hline \multicolumn{10}{|c|}{ Average $B W / T W$ ratio } & 0.6 \\
\hline
\end{tabular}

The 13 rills and ephemeral gullies that were mapped in the field range between 3.2 and $47 \mathrm{~m}$ in length. A total of 95 cross sections were measured; the areas ranged from 0.01 to $0.36 \mathrm{~m}^{2}$, and the average area was $0.11 \mathrm{~m}^{2}$. To evaluate the mean value of the $B W / T W$ (bottom width/top width) ratio, each of the cross sections that were measured in the field was approximated by a trapezoid.

\subsection{Measurement Uncertainty}

\subsubsection{Accuracy of Satellite Height Measurements}

Figure 11C shows the correlation between the heights that were measured in the field and those that were measured from the satellite stereo images using the 3D floating cursor. The inset in Figure 11C shows the uncertainty that is associated with the channel depth satellite measurements that are modelled by assuming a normal distribution (mean value of 0.002 and standard deviation of 0.059 ).

\subsubsection{Volume Estimation and Associated Error}

The volumes and lengths of the SMC subset were used to estimate the $V$ - $L$ relationships for the rills and the ephemeral gullies. Figure 12 shows the results of the regressions. Both regressions are characterized by high coefficients of determination $\left(R^{2}=0.5\right.$ for rills and $R^{2}=0.47$ for gullies). 
Additionally, the probability of rejection ( $p$ value), which was calculated using the one-tail Pearson's correlation coefficient test, is less than 0.0005 .
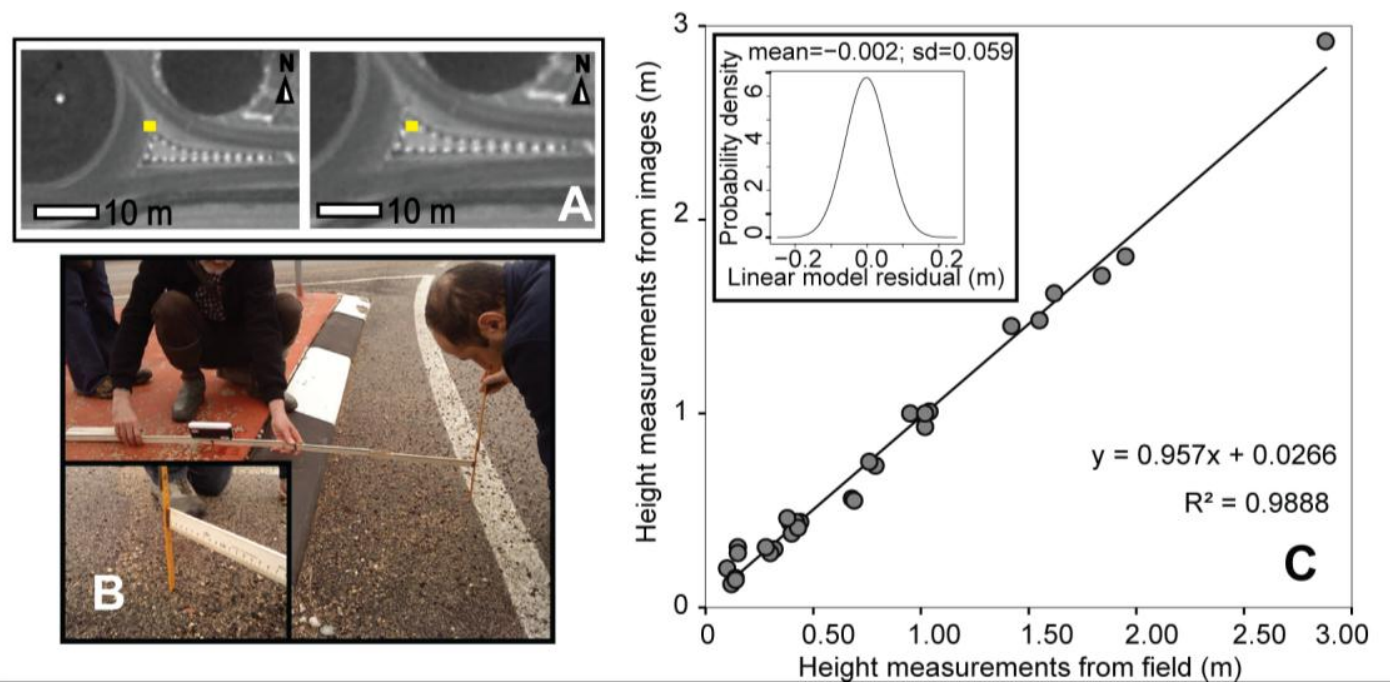

Figure 11. (A) Example of an object that was selected as a reference during the field survey (the points that were used to calculate and measure the height difference are shown in green). (B) Measurement of the height difference of a stable object in the field. (C) Correlation between the heights that were measured in the field and the corresponding heights that were derived from the satellite stereo images. The inset shows the error, which is modelled by a normal distribution.
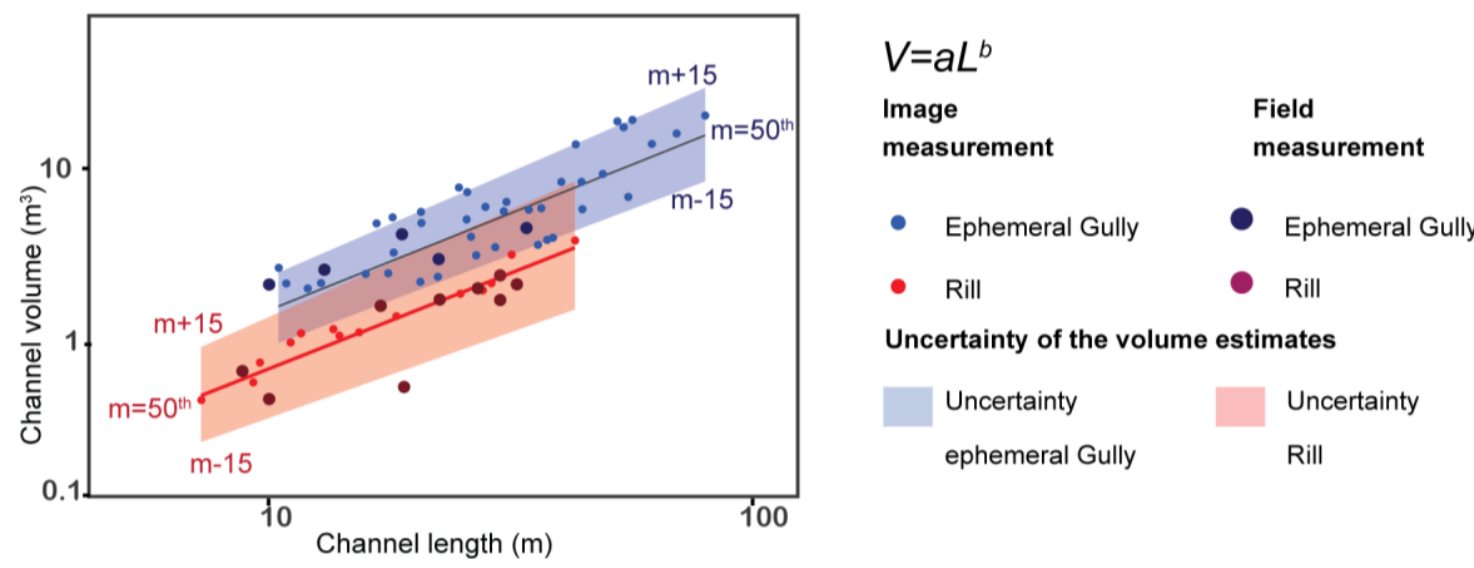

Figure 12. Power law relationship $\left(V=a L^{b}\right)$ in a bi-logarithmic diagram for the rills and ephemeral gullies and the associated uncertainties. The small blue and red dots are the ephemeral gully volumes and rill volumes, respectively, which were measured using the stereo satellite images, and the large blue and red dots are the volumes of the rills and gullies, respectively, which were measured in the field. The uncertainties that are associated with the power law fits for the rills (red shaded area) and ephemeral gullies (blue shaded area) are defined based on the 35 th percentile $(m-15)$ and the 65 th percentile $(m+15)$, respectively, of the power law parameters $a$ and $b$. 
To consider the uncertainty of the channel depth estimates (which contributes to the uncertainty of the volume estimates), we compared the data that were collected during the height measurement survey (the height calibration curve in Section 5.4.1). Despite the high values of the $\mathrm{R}^{2}$ coefficients, which ensure a high significance of the relationships with $p<0.0005$, normally distributed errors are still associated with the measurements. By applying the bootstrap techniques that were described in Section 4.6.2, we generated error lines that correspond to the 35 th and 65 th percentiles of the errors that are associated with the estimated parameters $a$ and $b$ for the two volume-length relationships (Table 4). Figure 13 shows the quantile-quantile plot of the modelled and measured heights and the Kolmogorov-Smirnov test results. The shaded area in Figure 12 represents the uncertainties in the volumes that were estimated using the best-fitting values for the rills and ephemeral gullies. The value of $b$ controls the length-dependent variation in the cross-sectional area. Larger values of $b$ are associated with larger cross-sectional areas and longer channel lengths [36]. The $b$ coefficients range from 1.04 to 1.30 (35th and 65th percentiles) for the rills and from 1.15 to 1.24 (35th and 65th percentiles) for the gullies (Table 4).

Table 4. Values of the coefficients $a$ and $b$ from the interpolation of the data that were collected using the satellite stereo-pairs. The values of the coefficients $a$ and $b$ include the 35 th percentile (minimum value), the 65 th percentile (maximum value) and the median value of the parameter distribution. The total eroded volume is estimated as the sum of the volumes of the 555 channels. The weight of the eroded volume is based on a medium with a density of $\gamma=1.6 \mathrm{Mg} \cdot \mathrm{m}^{-3}[62]$.

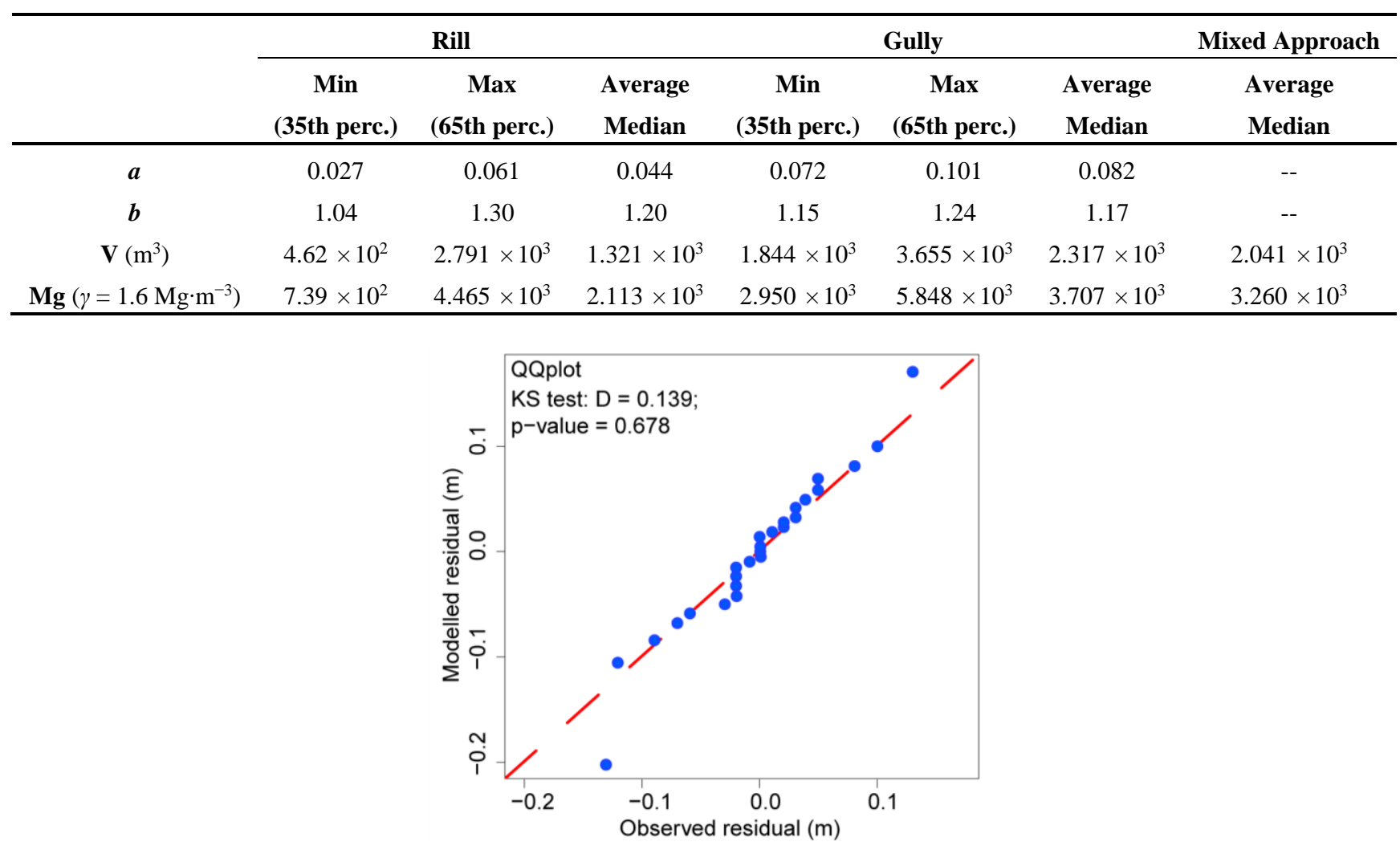

Figure 13. Kolmogorov-Smirnov test (KS) and the quantile-quantile (QQ) plot of the modelled and measured errors. 
The $B W / T W$ ratio influences the dimensions of the CS and the estimated volume. The error that is associated with the selection of the $B W / T W$ ratio was evaluated. The best fit that was obtained for the 50th percentile for several values of $B W / T W$ is shown in Figure 14. Because the field observations have $B W / T W$ ratios between 0.3 and 0.7 , the error due to the assumption of a constant $B W / T W$ ratio is approximately half of the error due to the error that is associated with the depth (shaded area).

The volumes of the rill and gully channels that were measured in the field were compared with those that were estimated from the stereo images. In Figures 12 and 14, the large dark blue and red dots represent the volumes of the rills and gullies in the field, whereas the smaller dots represent the volumes that were estimated from the satellite data. The field values refer to new channels, which were measured in a different year but under similar land-use and rainfall conditions (Section 5.1). The field values can serve as a general reference for evaluating the reliability of satellite measurements. In particular, the field-based volume measurements fall well inside the shaded area that represents the uncertainty that is associated with the volume-length relationship from the satellite stereo images.

\subsection{Eroded Volumes and Denudation}

The total eroded volumes for the study area were simulated (i) for the extreme cases in which the channels were all rills or all gullies and (ii) for the mixed approach (in which a fraction of the channel segments are considered as rills and the remaining as gullies, based on the length of the channel segment). Tables 2 and 3 show that rill segments are never longer than $43.4 \mathrm{~m}$ (SMC data) or $47 \mathrm{~m}$ (field survey). The gully segments are never less than $10 \mathrm{~m}$ (field survey) or $10.6 \mathrm{~m}$ (SMC data) long. Hence, in the mixed approach we use the rill volume equation if the segment is shorter than $10 \mathrm{~m}$ and the gully volume equation if it is longer than $47 \mathrm{~m}$. If the segment is between $10 \mathrm{~m}$ and $47 \mathrm{~m}$ long, we arbitrarily use the average of the rill and gully volumes.

Table 5. Erosion in $\mathrm{Mg} \cdot \mathrm{ha}^{-1}$ and denudation in $\mathrm{mm}$ for the entire catchment (total surface area: $\left.48 \mathrm{~km}^{2}\right)$, cropland/seed-bed conditions $\left(5.92 \mathrm{~km}^{2}\right.$ ) and the parcels that were affected by rill and gully erosion $\left(1.149 \mathrm{~km}^{2}\right)$ based on the values of the coefficients $a$ and $b$ for the rills and gullies for the 35 th percentile (minimum value), 65 th percentile (maximum value) and median value.

\begin{tabular}{|c|c|c|c|c|c|c|c|}
\hline & & \multicolumn{2}{|c|}{$\begin{array}{l}\text { Catchment } \\
A=48 \mathbf{k m}^{2}\end{array}$} & \multicolumn{2}{|c|}{$\begin{array}{c}\text { Cropland Seed-Bed Condition } \\
\qquad \mathrm{A}=5.92 \mathrm{~km}^{2}\end{array}$} & \multicolumn{2}{|c|}{$\begin{array}{l}\text { Affected Parcels } \\
\mathrm{A}=1.149 \mathbf{k m}^{\mathbf{2}}\end{array}$} \\
\hline & & 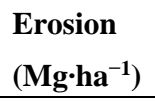 & $\begin{array}{l}\text { Denudation } \\
(\mathbf{m m})\end{array}$ & $\begin{array}{l}\text { Erosion } \\
\left(\mathbf{M g}^{\prime} \mathbf{h a}^{-1}\right)\end{array}$ & $\begin{array}{l}\text { Denudation } \\
(\mathbf{m m})\end{array}$ & $\begin{array}{l}\text { Erosion } \\
\left({\left.\mathrm{Mg} \cdot h a^{-1}\right)}\right.\end{array}$ & $\begin{array}{l}\text { Denudation } \\
(\mathbf{m m})\end{array}$ \\
\hline \multirow{3}{*}{ Rill } & Min (35th perc.) & 0.153 & 0.010 & 1.248 & 0.078 & 6.427 & 0.402 \\
\hline & Max (65th perc.) & 0.930 & 0.0581 & 7.544 & 0.471 & 38.833 & 2.429 \\
\hline & Average (median) & 0.440 & 0.027 & 3.571 & 0.223 & 18.382 & 1.150 \\
\hline \multirow{3}{*}{ Gully } & Min (35th perc.) & 0.614 & 0.038 & 4.985 & 0.311 & 25.661 & 1.605 \\
\hline & Max (65th perc.) & 1.218 & 0.076 & 9.880 & 0.617 & 50.860 & 3.181 \\
\hline & Average (median) & 0.772 & 0.048 & 6.263 & 0.391 & 32.242 & 2.017 \\
\hline $\begin{array}{c}\text { Mixed } \\
\text { Approach }\end{array}$ & Average (median) & 0.680 & 0.043 & 5.517 & 0.344 & 28.401 & 1.776 \\
\hline
\end{tabular}


The results are given in Table 5, which summarizes the eroded soil and denudation respectively in terms of tonnes per hectare $\left(\mathrm{Mg} \cdot \mathrm{ha}^{-1}\right)$ and volume per unit area $(\mathrm{mm})$. The total erosion and denudation refer to three areas: (i) the entire catchment $\left(48 \mathrm{~km}^{2}\right)$, (ii) only to the land that is affected by rills and ephemeral gullies (cropland under seed-bed conditions; $5.92 \mathrm{~km}^{2}$ ), and (iii) only the fields where channel erosion took place $\left(1.149 \mathrm{~km}^{2}\right)$

\section{Discussion}

Previous attempts to use stereoscopic satellite images (e.g., [36,37]) have consisted of the recognition, measurement and mapping of medium to large gullies. In our experiment, VHR (i.e., $0.5 \mathrm{~m}$ spatial resolution) stereoscopic satellite images were used to detect, map and measure ephemeral gullies and rills that are easily removed by agricultural practices or hidden by vegetation growth; hence, this study identified and measured channel features at a more detailed scale.

The lengths and widths of channels have been measured in the previous studies because they are usually derived from monoscopic satellite images [63]. This has been overcome by low-altitude UAV photogrammetry because it uses stereo pairs that allow millimetric resolutions [64]. These types of extremely detailed measurements are generally not applicable to medium size catchment (i.e., $>20-25 \mathrm{~km}^{2}$ ) because of the extensive field surveys and complex post-processing operations that are required to orient the large number of aerial photographs. The use of VHR satellite stereo pairs allows us to study large catchment with only one pair and generally requires only a few GCPs to improve the accuracy of the orientation.

Because rill and gully erosion networks are often anastomosing, it was necessary to subdivide channels into segments between successive nodes (head/end channel points and channel branches).

In this experiment, the rill and gully depths could only be measured along some of the channel segments (SMC subset). The width, length and depth measurements allowed the calculation of the channel volumes and the values of the coefficients $a$ and $b$ that were the result of the interpolation of the channel volume-length $(V-L)$ data. Because the depth measurements depend on the ability of the photo-interpreters to use floating cursor techniques, the proposed approach evaluates the depth-measurement uncertainty and its impact on the estimated eroded volumes. The shaded areas in Figure 12 represent the uncertainties in the volumes that were estimated using the best-fitting values for the rills and ephemeral gullies. The uncertainty of the rill volume is greater than the uncertainty of the gully volume, which indicates that the error in the depth measurements has a larger effect on the volume estimates of rills.

Among the other sources of error, the effect of changing the shape of the channel cross section from triangular $(\mathrm{BW} / \mathrm{TW}=0)$ through trapezoidal $(0<\mathrm{BW} / \mathrm{TW}<1)$ to rectangular $(\mathrm{BW} / \mathrm{TW}=1)$ was also evaluated. The cross-sectional shape (i.e., $B W / T W$ ) was found to have a smaller effect on the volume estimation than the depth error. Hence, the use of the field-data derived average TW/BW ratio to estimate cross section to obtain gully and rill volume from satellite images has a negligible effect on the volume estimation.

The values of the coefficients $a$ and $b$ for the ephemeral gully that were obtained in this study were in the range of values that have been obtained by several authors from field data (Table 6) [54-58], which suggests that the satellite stereoscopic images can provide reliable measurements to characterize the sizes of gullies and rills. When these trends were compared with the rill and gully channel data that 
were collected during a field survey in the same area, we obtained a reasonable agreement with the calculated trends. The comparison is possible because the rainfall conditions that triggered the erosion channels in the two periods were similar (maximum rainfall intensity in the two periods is $14 \mathrm{~mm} \cdot \mathrm{h}^{-1}$ ). Therefore, satellite images can be used to acquire information in areas that are affected by channeled erosion and to characterize transient erosion features, such as ephemeral gullies and rills in agricultural areas.

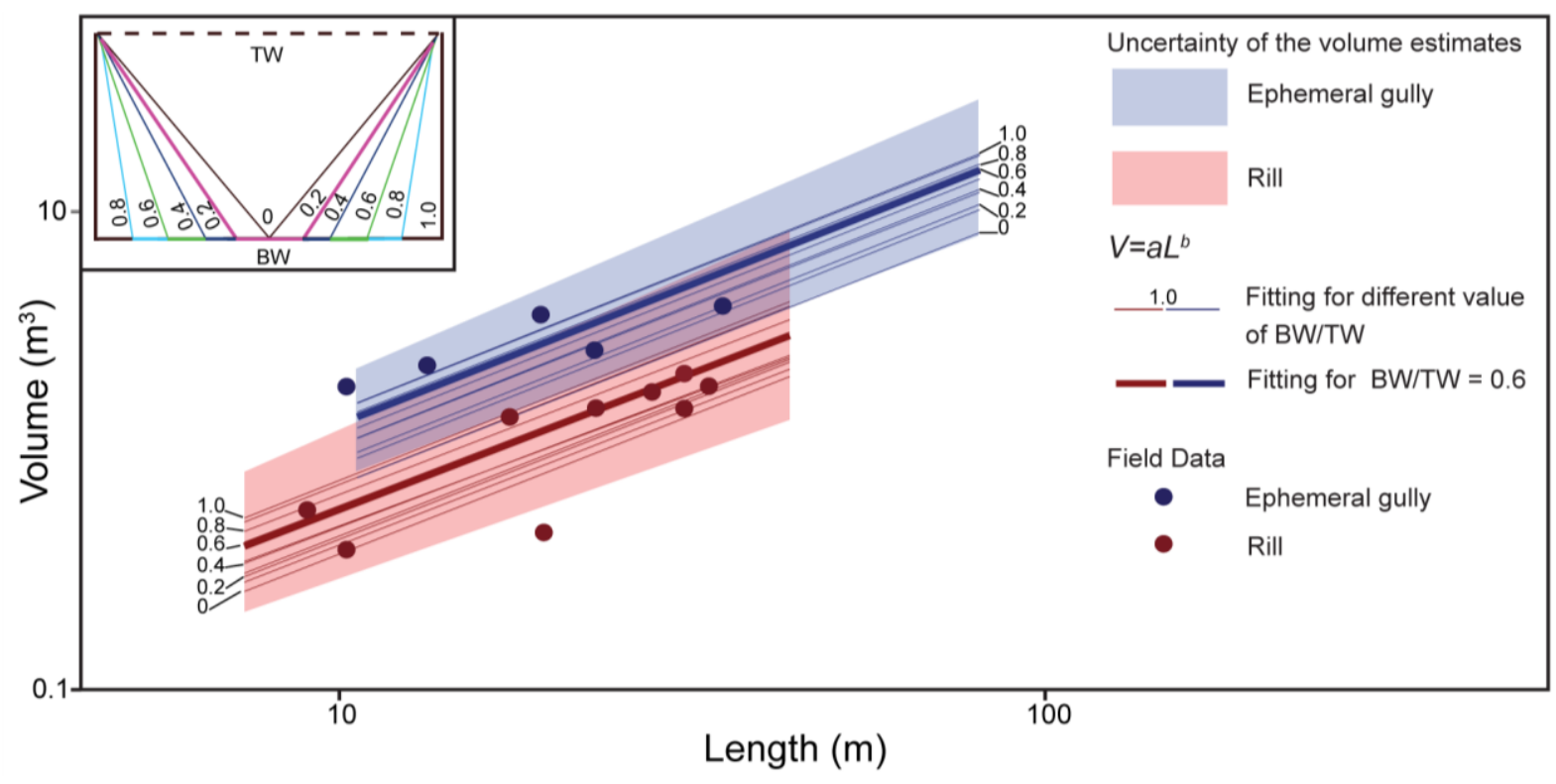

Figure 14. Analysis of the influence of $B W / T W$ on the estimation of the volumes. A sketch of cross sections with different values of $B W / T W$ is shown in the inset, different colors of the lines correspond to different value of the $B W / T W$. The thin lines represent the fit for the 50th percentile of the $V-L$ relationship that was obtained for different $B W / T W$ values, and the thick lines are the fits that were obtained for $B W / T W=0.6$. The shaded areas represent the uncertainty of the volume estimates of the power law fits that is related to the error in the depth evaluation (Figure 12). The dots represent the volumes and lengths of the rills and ephemeral gullies that were measured in the field.

Table 6. Values of the coefficients $a$ and $b$ from the interpolation of the data that were collected from satellite stereo-pairs and the coefficients for ephemeral gullies that were obtained by several authors.

\begin{tabular}{|c|c|c|c|c|c|c|}
\hline Authors & {$[54,56]$} & [55] & [56] & [57] & [58] & $\begin{array}{c}\text { This } \\
\text { Experiment }\end{array}$ \\
\hline $\begin{array}{l}\text { Study } \\
\text { area }\end{array}$ & Spain & Belgium & $\begin{array}{l}\text { Sicily } \\
\text { (Italy) }\end{array}$ & $\begin{array}{l}\text { Sicily } \\
\text { (Italy) }\end{array}$ & $\begin{array}{l}\text { Sicily } \\
\text { (Italy) }\end{array}$ & $\begin{array}{l}\text { Umbria } \\
\text { (Italy) }\end{array}$ \\
\hline$a$ & 0.054 & 0.048 & 0.082 & 0.034 & 0.812 & 0.082 \\
\hline$b$ & 1.0 .37 & 1.29 & 1.416 & 1.42 & $1 . .062$ & 1.174 \\
\hline
\end{tabular}

Distinguishing rills from gullies is a key step for correctly estimating the eroded volume. Table 4 shows that the rill volume that was estimated using the $a$ and $b$ parameters of the $V$ - $L$ relationship that corresponds to the 65 th percentile is 6 times the volume that was estimated for the 35 th percentile, while 
for the gullies, the volume that corresponds to the 65th percentile is 1.9 times the volume that was estimated for the 35th percentile. This result demonstrates the importance of the error in the depth estimation, especially for small depths (in the SMC the average rill depth is $11 \mathrm{~cm}$, while the average gully depth is $20 \mathrm{~cm}$ ).

The differences between considering the all-rill case versus the all-gully case ( $a$ and $b$ parameters of the 50th percentile) result in a gully/rill ratio of 1.8 ; hence, the two cases add a further non-negligible uncertainty to the volume estimate. This difference decreases if we use the mixed approach, which recognized rills and gullies based on the segment length. The mixed approach suggests eroded values that are 1.5 times greater than the all-rill case and 0.9 times smaller than the all-gully case.

Assuming that the mixed approach provides the most realistic estimate, we can compare the estimate from the mixed approach to values of erosion from the literature. In particular, a value of approximately $0.5 \mathrm{Mg} \cdot \mathrm{ha}^{-1}$ can be deduced from the data in Torri et al. ([65]) over the same period (i.e., 2.5 months), which is comparable to the erosion value at the catchment scale $\left(0.680 \mathrm{Mg} \cdot \mathrm{ha}^{-1}\right)$. At the field scale (i.e., the affected parcels), the mixed approach suggests erosion of $28.4 \mathrm{Mg} \cdot \mathrm{ha}^{-1}$, which falls within the values of gully erosion from the literature (i.e., 9-90 Mg.ha ${ }^{-1}$ over 2.5 months $[7,66]$ ). The fields that are affected by linear erosion are subject to intense erosion with a total denudation that is $1.77 \mathrm{~mm}$, greater than the expected pedogenization for a substantially mature soil (e.g., Alexandrovskiy [67], who reported erosion of approximately $0.1-0.07 \mathrm{~mm}$ in 2.5 months for a 1-2 ka luvisol).

Our results indicate that erosion at the catchment scale is moderate $[68,69]$, whereas the erosion at the field scale exceeds the tolerance limit, which is consistent with data that have been summarized and/or discussed by several authors [70,71].

Despite these advantages, the methodology that we described for the measurement of rills and gully channels has certain limitations. This analysis requires that operators be skilled at using the 3D floating cursor mapping approach. In particular, the operator must position the floating cursor correctly on the ground to obtain realistic measurements of an object's height. Second, the analysis must be performed during fixed illumination conditions of the day of the satellite acquisition. As suggested by Giménez [72], certain illumination conditions can result in an inaccurate depth estimates of narrow erosional channels (i.e., when the $T W / D$ ratio is less than 2.5). These problems were limited in our analysis because the satellite images were taken under adequate illumination conditions (27 May 2010, at 10:06 am GMT, 11:06 am local time in Italy; the local sun azimuth was $121.06^{\circ}$ with an elevation of $56.63^{\circ}$ ), and the images were used to map shallow rills and gully channels with an average $T W / D$ ratio of 8.9. However, these conditions limit the time window during which images should be acquired.

The use of very high-resolution stereoscopic satellite images allows the mapping of erosional phenomena over a short period of time compared to the time that is usually required for field survey mapping. Nachtergaele and Poesen [5] estimated that a $2 \mathrm{~km}^{2}$ field survey requires two people and a full day to obtain basic data. Conversely, one person can map and measure the erosional features in an area of approximately $20 \mathrm{~km}^{2}$ in one day using a satellite stereo-pair. Moreover, VHR stereoscopic satellite images can cover a much larger area in a single frame than traditional aerial photographs. In fact, the minimum area of a stereoscopic commercial satellite image is $100 \mathrm{~km}^{2}$. When studying these surface phenomena at the basin scale or at least across very large areas, the wider overview that is provided by satellite images can limit the omission of features that are typically missed during field investigations [5]. Moreover, this method is more useful than field surveys for estimating ephemeral erosion channels in 
remote areas or in places that are hard to reach; these estimates can even be made months after the occurrence of ephemeral gullies and rills and when the features have been destroyed by farming activities.

The proposed method involves many aspects, including the aforementioned skill of the operator, the spatial resolutions and the quality of the stereoscopic satellite images, and the time span during which the correct illumination is achieved. The spatial resolution has a strong influence on the size of the linear erosion features that can be detected [63]. The quality of the image is fundamental for detecting small features, such as rills or ephemeral gullies, and includes photographic aspects such as the contrast, brightness and haze. In particular, the ability to detect and map rills and gullies is related to the contrast between the channel and the surrounding objects and can be emphasized dynamically changing the contrast. Furthermore, the stereovision allows data to be obtained at an apparent resolution that is better than the nominal resolution (i.e., pixel size; $50 \mathrm{~cm}$ in our case). Despratts [63] showed values that were smaller than the nominal resolution. This may be due to the simple geometrical effect of a 3D view with respect to a $2 \mathrm{D}$ view (single image). During the internal process of reconstructing an image, the brain can actually increase the resolution. Unfortunately, we do not have sufficient data to control this aspect with proper ground truth. Hence, we decided to only explore channels larger than $50 \mathrm{~cm}$.

\section{Conclusions}

In this study, we proposed a new methodology for mapping and measuring rills and ephemeral gullies using very high-resolution GeoEye- $1{ }^{\circledR}$ panchromatic stereo images. This new methodology was successfully applied and tested to recognize, map and measure relatively small channels, such as rills and ephemeral gullies. The proposed method is faster than classical field surveys, improves the ability to map these features over large areas, and complements UAV-based surveys, which are applicable to detailed scales and analyses, and other more traditional methods. Moreover, the availability of archive images allows this method to be used to map ephemeral channels that were removed by farming activities, which improves the analysis of erosion over time.

The results that were obtained in this study were consistent with a local field survey and, more generally, with results from the literature, which confirms that satellite stereo pairs can provide reliable estimates of ephemeral gully and rill erosion. The field-surveyed rill and gully data plot within the error band around the satellite-based volume-length relationship. Furthermore, the values of the coefficients of the volume-length relationship $(a=0.082 ; b=1.174)$ are within the range of ephemeral gully values that were observed by other authors. The method was also applied to estimate the eroded volume from a large area $\left(48 \mathrm{~km}^{2}\right)$ by incorporating the uncertainty into the $V$ - $L$ relationship based on the uncertainty that is associated with the channel depth measurements. The calculated erosion value (mixed approach) at the scale of fields that were affected by channeled erosion $\left(1.14 \mathrm{~km}^{2}\right)$ was $28.4 \mathrm{Mg} \cdot \mathrm{ha}^{-1}$ over 2.5 months. At the catchment scale $\left(48 \mathrm{~km}^{2}\right)$, the erosion value is $0.68 \mathrm{Mg} \cdot \mathrm{ha}^{-1}$. In addition to the methodological results, this study provides the first estimate of gully and rill erosion in a medium-size mountain catchment in Central Italy and complements numerical studies that have been conducted in other areas, such as Sicily [56].

The proposed methodology can easily be applied wherever stereoscopic satellite images are available provided that the illumination conditions and channel width/depth constraints are satisfied. We consider 
this methodology of using very high-resolution stereoscopic satellite images to be particularly useful for building extensive and reliable databases of ephemeral erosional features over large areas.

\section{Acknowledgements}

The hardware and software systems were funded through the ASI MORFEO project. Federica Fiorucci was supported by the Regione dell’Umbria grant PoR-FESR 861, 2012. The authors are grateful to Amaury Frankl for his comments, which substantially improved the manuscript. The authors are also in debt to Mark Griffiths and Kara Guglielmino for their revisions, which strongly improved the text.

\section{Author Contributions}

Federica Fiorucci prepared the oriented stereo images, mapped and measured the rill and gully channels, and assessed the accuracy of the height measurements. Mauro Rossi performed the statistical analyses. Francesca Ardizzone and Dino Torri supervised the work. All of the authors participated in the field surveys and contributed to the composition of this paper.

\section{Conflicts of Interest}

The authors declare no conflict of interest.

\section{References}

1. Poesen, J.W.A.; Torri, D.B.; Vanwalleghem, T. Gully erosion: Procedures to adopt when modelling soil erosion in landscapes affected by gullying. In Handbook of Erosion Modelling, Morgan, R.P.C., Nearing, M.A., Eds.; John Wiley \& Sons: Chichester, UK, 2010; pp. 360-386.

2. Torri, D.; Borselli, L. Equation for high-rate gully erosion. Catena 2003, 50, 449-467.

3. Borselli, L.; Cassi, P.; Torri, D. Prolegomena to sediment and flow connectivity in the landscape: A GIS and field numerical assessment. Catena 2008, 75, 268-277.

4. Vigiak, O.; Newham, L.T.H.; Whitford, J.; Melland, A.; Borselli, L. Comparison of landscape approaches to define spatial patterns of hillslope-scale sediment delivery ratio. In Proceedings of 18th World IMACS/MODSIM Congress, Cairns, QLD, Australia, 13-17 July 2009.

5. Nachtergaele, J.; Poesen, J. Assessment of soil losses by ephemeral gully erosion using high altitude (stereo) aerial photographs. Earth Surf. Process. Landf. 1999, 24, 693-706.

6. Torri, D.; Regües Muñoz, D.; Pellegrini, S.; Bazzoffi, P. Within-Storm soil surface dynamics and erosive effects of rainstorms. Catena 1999, 38, 131-150.

7. Bazzofi, P.; Chisci, G.; Missere, D. Influenza delle opere di livellamento e scasso sull'erosione del suolo nella collina cesenate. Riv. Agron. 1989. 23, 609-221.

8. Kosov, B.F.; Kostantinova, G.S. Zoning the USSR territory by the density of gullies. Eroziia pochv i ruslovye protsessy. 1972, 4, 15-24. (In Russian).

9. Nordström, K. Gully Erosion in the Lesotho Lowlands. A Geomorphological Study of the Interactions between Intrinsic and Extrinsic Variables. Ph.D. Thesis, Uppsala University, Uppsala, Sweden, 1988. 
10. Casalí, J.; Loizu, J.; Campo, M.A.; de Santisteban, L.M.; Alvarez-Mozos, J. Accuracy of methods for field assessment of rill and ephemeral gully erosion. Catena 2006, 67, 128-138.

11. Moody, J.A.; Kinner, D.A. Spatial structures of stream and hillslope drainage networks following gully erosion after wildfire. Earth Surf. Process. Landf. 2006, 31, 319-337.

12. Nyssen, J.; Poesen, J.; Veyret-Picot, M.; Moeyersons, J.; Haile, M.; Deckers, J.; Dewit, J.; Naudts, J.; Teka, K.; Govers, G. Assessment of gully erosion rates through interviews and measurements: a case study from northern Ethiopia. Earth Surf. Process. Landf. 2006, 31, 167-185.

13. Ahmadov, H.M. Gully erosion rate in Tadjikistan. Gheomorfologhia 1977, 5, 51-55. (In Russian)

14. Bocco, G. Gully erosion: Processes and models. Prog. Phys. Geogr. 1991, 15, 392-406.

15. Burkard, M.B.; Kostaschuk, R.A. Patterns and controls of gully growth along the shoreline of Lake Huron. Earth Surf. Process. Landf. 1997, 22, 901-911.

16. Pellikkaa, P.K.E.; Clarka, B.J.F.; Sirviöa, T.; Masalina, K. Environmental change monitoring applying satellite and airborne remote sensing data in the Taita Hills, Kenya. In Proceedings of the 1st International Conference on Remote Sensing and Geoinformation Processing in the Assessment and Monitoring of Land Degradation and Desertification, Trier, Germany, 7-9 September 2005; pp. 223-232.

17. Marzolff, I.; Poesen, J. The potential of 3D gully monitoring with GIS using high resolution aerial photography and a digital photogrammetry system. Geomorphology 2009, 111, 48-60.

18. Perroy, R.L.; Bookhagen, B.; Asner, G.P.; Chadwick, O.A. Comparison of gully erosion estimates using airborne and ground-based LiDAR on Santa Cruz Island, California. Geomorphology 2010, $118,288-300$.

19. D’Oleire-Oltmanns, S.; Marzolff, I.; Peter, K.D.; Ries, J.B. Unmanned Aerial Vehicle (UAV) for monitoring soil erosion in Morocco. Remote Sens. 2012, 4, 3390-3416.

20. Peter, K.D.; d'Oleire-Oltmanns, S.; Ries, J.B.; Marzolff, I.; Hssaine, A.A. Soil erosion in gully catchments affected by land-levelling measures in the Souss Basin, Morocco, analyzed by rainfall simulation and UAV remote sensing data. Catena 2014, 113, 24-40.

21. Kaiser, A.; Neugirg, F.; Rock, G.; Müller, C.; Haas, F.; Ries, J.; Schmidt, J. Small-Scale surface reconstruction and volume calculation of soil erosion in complex Moroccan gully morphology using structure from motion. Remote Sens. 2014, 6, 7050-7080.

22. Gómez-Gutiérrez, Á.; Schnabel, S.; Berenguer-Sempere, F.; Lavado-Contador, F.; Rubio-Delgado, J. Using 3D photo-reconstruction methods to estimate gully headcut erosion. Catena 2014, 120, 91-101.

23. Frankl, A.; Stal, C.; Abraha, A.; Nyssen, J.; Rieke-Zapp, D.; De Wulf, A.; Poesen, J. Detailed recording of gully morphology in 3D through image-based modelling. Catena 2015, 127, 92-101.

24. Watson, A.; Evans, R.A. Comparison of estimates of soil erosion made in the field and from photographs. Soil Tillage Res. 1991, 19, 17-27.

25. Keech, M.A. The photogrammetric evaluation of areal and volumetric change in a gully in Zimbabwe. In Erosion, Conservation and Small Scale Farming; Hurni, H., Tato, K., Eds.; Geographica Bernensia: Bern, Switzerland, 1992; pp. 51-52.

26. Price, K.P. Detection of soil erosion within pinyon-juniper woodlands using Thematic Mapper (TM) data. Remote Sens. Environ. 1993, 45, 233-248.

27. Pickup, G.; Nelson, J. Use of Landsat radiance parameters to distinguish soil erosion, stability, and deposition in arid Central Australia. Remote Sens. Environ. 1984, 16, 195-209. 
28. Pickup, G.; Chewings, V.H. Forecasting patterns of soil erosion in arid lands from Landsat MSS data. Int. J. Remote Sens. 1988, 9, 69-84.

29. Langran, KJ. Potential for monitoring soil erosion features and soil erosion modelling components from remotely sensed data. In Proceedings of IGARSS'83, San Francisco, CA, USA, 1-4 February 1983.

30. Millington A.C.; Townshend J.R.G. Remote sensing applications in African erosion and sedimentation studies. In Challenges in African Hydrology and Water Resources: Proceedings of the Harare Symposium; Walling, D.E., Foster, S.S.D., Wurzel, P., Eds.; IAHS Publication: Oxfordshire, UK, 1984; pp. 373-384.

31. Bouaziz, M.; Wijaya, A.; Gloaguen, R. Gully erosion mapping using aster data and drainage network analysis in the main Ethiopian rift. In Proceedings of the International Geoscience and Remote Sensing Symposium (IRARSS), Cape Town, South Africa, 12-17 July 2009; pp. I13-I16.

32. Vrieling, A.; de Jong, S.M.; Sterk, G.; Rodrigues, S.C. Timing of erosion and satellite data: A multi-resolution approach to soil erosion risk mapping. Int. J. Appl. Earth Obs. Geoinf. 2008, 10, 267-281.

33. Knight, J.; Spencer, J.; Brooks, A.; Phinn, S. Large-Area, high-resolution remote sensing based mapping of alluvial gully erosion in Australia's tropical rivers. In Proceedings of the 5th Australian Stream Management Conference: Australian Rivers, Making a Difference, Thurgoona, NSW, Australia, 21-25 May 2007; pp. 199-204.

34. Shruthi, R.B.V.; Kerle, N.; Jetten, V. Object-based gully feature extraction using high resolution imagery. Geomorphology 2011, 134, 260-268.

35. Frankl, A.; Zwertvaegher, A.; Poesen, J.; de Dapper, M.; Nyssen, J. Transferring Google Earth observations to GIS-software: Example from gully erosion study. Int. J. Digit. Earth 2013, 6, 196-201.

36. Frankl, A.; Poesen, J.; Scholiers, N.; Jacob, M.; Haile, M.; Deckers, J.; Nyssen, J. Factors controlling the morphology and volume (V)-length (L) relations of permanent gullies in the Northern Ethiopian Highlands. Earth Surf. Process. Landf. 2013, 38, 1672-1684.

37. Sattar, F.; Wasson, R.; Pearson, D.; Boggs, G.; Ahmad, W.; Nawaz, M. The development of geoinformatics based framework to quantify gully erosion. In Proceedings of the International Multidisciplinary Scientific Geo-Conference \& Expo, Albena Resort, Bulgaria, 20-25 June 2010; pp. 1-9.

38. Conti, M.A.; Girotti, O. Il Villafranchiano nel "Lago Tiberino", ramo sud-occidentale: schema stratigrafico e tettonico. Geol. Romana 1977, 16, 67-80.

39. Servizio Geologico Nazionale Carta Geologica dell'Umbria. Map at 1:250 000 Scale; Litografia Artistica Cartografica: Firenze, Italy, 1980. (In Italian)

40. Cencetti, C. Il Villafranchiano della "riva umbra" del F. Tevere: Elementi di geomorfologia e di neotettonica. Boll. Soc. Geol. Ital. 1990, 109, 337-350. (In Italian)

41. Barchi. M.; Brozzetti. F.; Lavecchia. G. Analisi strutturale e geometrica dei bacini della media valle del Tevere e della valle umbra. Boll. Soc. Geol. Ital. 1991, 110, 65-76. (In Italian)

42. Fiorucci, F.; Cardinali, M.; Carlà, R.; Rossi, M.; Mondini, A.C.; Santurri, L.; Ardizzone, F.; Guzzetti, F. Seasonal landslides mapping and estimation of landslide mobilisation rates using aerial and satellite images. Geomorphology 2011, 129, 59-70. 
43. Ardizzone, F.; Fiorucci, F.; Santangelo, M.; Cardinali, M.; Mondini, A.; Rossi, M.; Reichenbach, P.; Guzzetti F. Very-high resolution stereoscopic satellite images for landslide mapping. In Landslide Inventory and Susceptibility and Hazard Zoning; Margottini, C., Canuti, P., Sassa, K., Eds.; Springer: Berlin, Germany, 2013; pp. 95-101.

44. Cardinali, M.; Ardizzone, F.; Galli, M.; Guzzetti, F.; Reichenbach, P. Landslides triggered by rapid snow melting: The December 1996-January 1997 event in Central Italy. In Proceedings of 1st Plinius Conference on Mediterranean Storms, Maratea, Italy, 14-16 October 1999; pp. 439-448.

45. Rossi, M.; Kirschbaum, D.; Luciani, S.; Mondini, A.C.; Guzzetti, F. TRMM satellite rainfall estimates for landslide early warning in Italy: Preliminary results. Proc. SPIE 2012, 8523, doi:10.1117/12.979672. Available online: http://dx.doi.org/10.1117/12.979672 (accessed on 20 July 2014).

46. Rossi, M.; Mondini, A.C.; Luciani, S.; Kirschbaum, D.; Valigi, D.; Guzzetti, F. Probabilistic prediction of landslides induced by rainfall. In Proceedings of the second International Conference on Vulnerability and Risk Analysis and Management (ICVRAM) and the Sixth International Symposium on Uncertainty Modelling and Analysis (ISUMA). Liverpool, UK, 13-16 July 2014.

47. Rossi, M.; Mondini, A.C.; Luciani, S.; Kirschbaum, D.; Valigi, D.; Guzzetti, F. A new probabilistic clustering approach for predicting rainfall induced landslides. In Proceedings of First International Workshop on Warning Criteria for Active Slides (IWWCAS), Courmayeur, Italy, 10-12 June 2013.

48. Stereo Analyst for ArcGIS; ERDAS Inc.: Norcross, GA, USA, 2009.

49. Planar SD2220W Stereoscopic Monitor User's Guide; Planar Systems: Beaverton, OR, USA, 2008.

50. Murillo-García, F.; Alcántara-Ayala, I.; Ardizzone, F.; Cardinali, M.; Fiorucci, F.; Guzzetti, F. Satellite stereoscopic pair images of very high resolution: A step forward for the development of landslide inventories. Landslides 2014, 12, 1-15.

51. Shaker, A.; Yan, W.Y.; Easa, S.M. Using stereo satellite imagery for topographic and transportation applications: An accuracy assessment. GISci. Remote Sens. 2010, 47, 321-337.

52. Hauge, C. Soil erosion definitions. California Geol. 1977, 30, 202-203.

53. Poesen, J. Gully typology and gully control measures in the European loess belt. In Proceedings of International Symposium on Farm Land Erosion in Temperate Plains Environment and Hills, Paris, France, 25-29 May 1992; pp.221-239.

54. Casalí, J.; Lopez, J.J.; Giràldez, J.V. Ephemeral gully erosion in southern Navarra (Spain). Catena 1999, 36, 65-84.

55. Nachtergaele, J.; Poesen, J.; Steegen, A.; Takken, I.; Beuselinck, L.; Vandekerckhove, L.; Govers, G. The value of a physically based model versus an empirical approach in the prediction of ephemeral gully erosion for loess-derived soils. Geomorphology 2001, 40, 237-252.

56. Capra, A.; Mazzara, LM.; Scicolone, B. Application of the EGEM model to predict ephemeral gully erosion in Sicily (Italy). Catena 2005, 59, 133-146.

57. Capra, A.; Di Stefano, C.; Ferro, V.; Scicolone, B. Similarity between morphological characteristics of rills and ephemeral gullies in Sicily, Italy. Hydrol. Process. 2009, 23, 3334-3341.

58. Di Stefano, C.; Ferro, V. Measurements of rill and gully erosion in Sicily. Hydrol. Process. 2011, 25, 2221-2227.

59. Efron, B. Bootstrap methods: Another look to the Jackknife. Ann. Stat. 1979, 7, 1-26.

60. Efron, B.; Tibshirani, R.J. An Introduction to the Bootstrap; Chapman and Hall: London, UK, 1993. 
61. R Core Team. R: A language and environment for statistical computing. R Foundation for Statistical Computing: Vienna, Austria, 2015.

62. Baccarini, L. Suscettibilità da frana nell'area di Collazzone (Umbria. Italia Centrale): applicazione di un modello distribuito fisicamente basato per scivolamenti profondi. Master's Thesis, Perugia University, Perugia, Italy, 2013. (In Italian)

63. Desprats, J.F.; Raclot, D.; Rousseau, M.; Cerdan, O.; Garcin, M.; Le Bissonnais, Y.; Ben Slimane, A.; Fouche, J.; Monfort-Climent, D. Mapping linear erosion features using high and very high resolution satellite imagery. Land Degrad. Dev. 2013, 24, 22-32.

64. Stöcker, C.; Eltner, A.; Karrasch, P. Measuring gullies by synergetic application of UAV and close range photogrammetry-A case study from Andalusia, Spain. Catena 2015, 132, 1-11.

65. Torri, D.; Borselli, L.; Guzzetti, F.; Calzolari, M.C.; Bazzoffi, P.; Ungaro, F.; Bartolini, D.; Salvador Sanchis, M.P. Italy. In Soil Erosion in Europe; Poesen, J., Boardman, J., Eds.; John Willey \& Son: West Sussex, UK, 2006; pp. 245-261.

66. Young. A. Present rate of land erosion. Nature 1969, 224, 851-852.

67. Alexandrovskiy A.L. Rates of soil-forming processes in three main models of pedogenesis. Rev. Mex. Cienc. Geol. 2007, 24, 283-292.

68. Poesen, J.; Nachtergaele, J.; Verstraeten, G.; Valentin, C. Gully erosion and environmental change: Importance and research needs. Catena 2003, 50, 91-133.

69. Poesen, J.; Vandekerckhove, L.; Nachtergaele, J.; Oostwoud Wijdenes, D.; Verstraeten, G.; van Wesemael, B. Gully erosion in dryland environments. In Dryland Rivers: Hydrology and Geomorphology of Semi-Arid Channels; Bull, L.J., Kirkby, M.J., Eds.; Wiley: Chichester, UK, 2002; pp. 229-262.

70. Aucelli, P.P.C.; Conforti, M.; Della Seta, M.; Del Monte, M.; D’uva, L.; Rosskopf, C.M.; Vergari, F. Multi temporal digital photogrammetric analysis for quantitative assessment of soil erosion rates in the Landola catchment of the Upper Orcia Valley (Tuscany, Italy). Land Degrad. Dev. 2014, doi:10.1002/ldr.2324. Available online: http://onlinelibrary.wiley.com/doi/10.1002/ldr.2324/epdf (accessed on 5 October 2014).

71. Della Seta, M.; del Monte, M.; Fredi, P.; Lupia Palmieri, E. Direct and indirect evaluation of denudation rates in Central Italy. Catena 2007, 71, 21-30.

72. Giménez, R.; Marzolff, I.; Campo, M.A.; Seeger, M.; Ries, J.B.; Casalí, J.; Álvarez-Mozos, J. Accuracy of high-resolution photogrammetric measurements of gullies with contrasting morphology. Earth Surf. Process. Landf. 2009, 34, 1915-1926.

(C) 2015 by the authors; licensee MDPI, Basel, Switzerland. This article is an open access article distributed under the terms and conditions of the Creative Commons Attribution license (http://creativecommons.org/licenses/by/4.0/). 